\title{
Knowledge Diversity and Coordination The Effect of Intrafirm Inventor Task Networks on Absorption Speed
}

\author{
Moreira, Solon; Markus, Arjan; Laursen, Keld
}

Document Version

Accepted author manuscript

Published in:

Strategic Management Journal

DOI:

10.1002/smj.2914

Publication date:

2018

License

Unspecified

Citation for published version (APA):

Moreira, S., Markus, A., \& Laursen, K. (2018). Knowledge Diversity and Coordination: The Effect of Intrafirm Inventor Task Networks on Absorption Speed. Strategic Management Journal, 39(9), 2517-2546.

https://doi.org/10.1002/smj.2914

Link to publication in CBS Research Portal

\section{General rights}

Copyright and moral rights for the publications made accessible in the public portal are retained by the authors and/or other copyright owners and it is a condition of accessing publications that users recognise and abide by the legal requirements associated with these rights.

Take down policy

If you believe that this document breaches copyright please contact us (research.lib@cbs.dk) providing details, and we will remove access to the work immediately and investigate your claim. 


\section{Knowledge Diversity and Coordination: The Effect of Intrafirm Inventor Task Networks on Absorption Speed Solon Moreira, Arjan Markus, and Keld Laursen}

Journal article (Accepted manuscript*

\section{Please cite this article as:}

Moreira, S., Markus, A., \& Laursen, K. (2018). Knowledge Diversity and Coordination: The Effect of Intrafirm Inventor Task Networks on Absorption Speed. Strategic Management Journal, 39(9), 2517-2546. https://doi.org/10.1002/smj.2914

This is the peer reviewed version of the article, which has been published in final form at DOI: https://doi.org/10.1002/smj.2914

This article may be used for non-commercial purposes in accordance with Wiley Terms and Conditions for Self-Archiving

* This version of the article has been accepted for publication and undergone full peer review but has not been through the copyediting, typesetting, pagination and proofreading process, which may lead to differences between this version and the publisher's final version AKA Version of Record. 


\title{
KNOWLEDGE DIVERSITY AND COORDINATION: THE EFFECT OF INTRAFIRM INVENTOR TASK NETWORKS ON ABSORPTION SPEED *
}

\section{SOLON MOREIRA}

Entrepreneurship Department

IESE Business School

Av. Pearson, 21, 08034, Barcelona

Telephone: +34 932536598

E-mail: smoreira@iese.edu

\author{
ARJAN MARKUS \\ Department of Organization Studies \\ Tilburg University \\ Professor Cobbenhagenlaan 225, 5037 DB Tilburg, The Netherlands \\ Telephone: +31 134662069 \\ E-mail: a.markus@tilburguniversity.edu \\ KELD LAURSEN \\ DRUID, Department of Innovation and Organizational Economics \\ Copenhagen Business School \\ Kilevej 14a, 2000 Frederiksberg, Denmark \\ and \\ Department of Industrial Economics and Technology Management \\ NTNU \\ 7491 Trondheim, Norway \\ E-mail: kl.ino@cbs.dk \\ Telephone: +45 38152565 \\ E-mail: kl.ino@cbs.dk \\ * All three authors contributed equally \\ Paper accepted for publication in the Strategic Management Journal.
}

Version: May 13, 2018, Word count, main body including footnotes: 10,263

Research summary: We combine the absorptive capacity and social network theory approaches to predict how intrafirm "whole" network characteristics affect the firm's rate of absorption of external knowledge to produce inventions. We start from the widely accepted view that distant, externally-developed knowledge is difficult to absorb into the focal firm's own knowledge production. We suggest that high levels of intrafirm inventor task network diversity and task network density are essential for a diversity of knowledge inputs and coordinated actions regarding knowledge transfer which in turn, reduces problems related to the absorption of knowledge-especially in the case of knowledge that is distant from the focal firm. The results of an event history study of 113 pharmaceutical firms that engaged in technology in-licensing from 1986-2003 provide general support for our hypotheses. 
Managerial summary: Firms keen to keep up with an uncertain and ever-changing industry environment, can benefit from the speedy introduction of inventions. We examine how firms absorb licensed-in technologies to nurture the rapid development of own related inventions. We show that a firm's absorption speed depends on the characteristics of the internal collaboration networks among the firm's inventor employees. More specifically, technologically diverse and well-connected inventor networks improve the firm's ability to absorb external technologies quickly. This applies especially to externally acquired technologies that are unfamiliar to the firm. Depending on the distance of the acquired technology from the focal firm combined with speed-inducing inventor network characteristics, our estimates suggest that firms can reduce the time needed for absorption by several months.

KEYWORDS: Absorption speed, absorptive capacity, intrafirm inventor networks, innovation, licensing 


\section{Knowledge Diversity and Coordination}

\section{INTRODUCTION}

Absorptive capacity — i.e., the ability to recognize, assimilate, and exploit external knowledge

— has become a critical theme in work on management that seeks to understand companies’ abilities to capture the returns from the external environment (Cohen and Levinthal, 1990; Lane and Lubatkin, 1998; Volberda, Foss, and Lyles, 2010). Prior research has identified a number of intraorganizational antecedents to firms' absorptive capacity, ranging from the presence of prior related knowledge to cross-functional interfaces (Jansen, van den Bosch, and Volberda, 2005; Volberda et al., 2010; Foss, Laursen, and Pedersen, 2011; Tortoriello, 2015). While this previous research has significantly increased our understanding of which organizational mechanisms have an impact on the firm's degree of absorptive capacity, the literature does not examine in depth how quickly organizations absorb external knowledge, or the precursors to absorption speed. In examining these issues, the present study responds to a call in the strategic management literature for studies explicitly addressing the issue of time (see e.g., George and Jones, 2000; Bridoux, Smith, and Grimm, 2011).

In industries where time-based competition and research and development (R\&D) races are paramount, companies benefit from quick integration of external knowledge (Kessler and Chakrabathi, 1996). Acquisition of external knowledge is an attractive alternative to in-house $\mathrm{R} \& \mathrm{D}$ and can shorten the invention development time. With some notable exceptions (Oxley and Wada, 2009; Leone and Reichstein, 2012; Tzabbar, Aharonson, and Amburgey, 2013), absorption speed and its related dimensions have received little empirical attention in the innovation literature. In the context of Japanese in-licensing from the U.S., Oxley and Wada (2009) demonstrate how joint venture participation accelerates the integration of external knowledge. In a sample that includes a wide set of industries, Leone and Reichstein (2012) show 


\section{Knowledge Diversity and Coordination}

that licensing-in fosters rapid invention, and highlight in particular, the role of contractual arrangements in that context. In the setting of the U.S. biotechnology industry, Tzabbar et al. (2013) show how prior accumulated experience based on scientist recruitment and alliance formation reduces the time needed to integrate knowledge from subsequent recruitment and alliance events. Despite this recent focus on absorption speed, and the consequent increased understanding of this topic, to the best of our knowledge there are no studies that explore the organizational determinants of the firm's ability to transform external knowledge quickly into own knowledge production.

Cohen and Levinthal (1990: 132-133) suggest that the "character and distribution of expertise" and the "internal structure of communication" should be considered the main organizational determinants of firms' levels of absorptive capacity. We take this conceptualization and the literature on as task relationship networks (e.g., Casciaro and Lobo, 2015; Fonti and Maoret, 2016) as our point of departure to explain how firms can rapidly assimilate and apply externally acquired knowledge in the context of technological innovation. Using a "whole" network perspective, we analyze how the "character and distribution of expertise" — reflected in intrafirm inventor task network diversity — and the "internal structure of communication” — reflected in intrafirm inventor task network density — affect organizations’ absorption speed. We also define an important boundary condition and study how the technological distance between the external knowledge acquired and the firm's knowledge base amplifies the importance of task relationship network characteristics for speedy knowledge absorption. In addressing these issues we seek also to respond to a recent call to examine how external knowledge is leveraged through within-organization relational exchanges (Tortoriello, 2015).

Our paper makes a distinct contribution compared to prior research on networks and 
innovation which focuses either on the role of single individuals in the integration of external knowledge (Tortoriello, 2015), or the role of individuals and whole networks in the recombination of internal knowledge (Guler and Nerkar, 2012; Carnabuci and Operti, 2013; Grigoriou and Rothaermel, 2014; Paruchuri and Awate, 2017). Paruchuri (2010) examines the interactions between inter- and intrafirm networks and their joint effects on innovation outcomes at firm level. Grigoriou and Rothaermel's (2017) study considers the interaction between external knowledge sourcing through alliances and acquisitions and intrafirm inventor network characteristics on the firm's innovative performance. However, neither of these studies explores how externally developed technologies are absorbed and used in the focal firm's future knowledge production.

We predict that inventor task network diversity and inventor task network density speed up the absorption process, especially in relation to the acquisition of technologically distant patents. We test these propositions in the context of the global licensing deals among 113 global pharmaceutical firms between 1986 and 2003. Given the significant R\&D investment needed to support the drug development process, pharmaceutical companies are especially eager to shorten the timeline from input to commercial success (Roberts and Hauptman, 1987; Cardinal, 2001; Macher and Boerner, 2006; Todorova and Durisin, 2007). Controlling for a wide set of organizational, network, and contractual factors that might influence absorption speed, we find support for our predictions.

\section{THEORETICAL BACKGROUND}

\section{Absorptive capacity and speed}

Grounded in the literature on organizational learning, Cohen and Levinthal (1990: 128) define the three components of absorptive capacity as "the ability of a firm to recognize the value of new, external information, assimilate it, and apply it to commercial ends”. This definition was 


\section{Knowledge Diversity and Coordination}

extended and modified in important ways by Zahra and George (2002), and later also by Todorova and Durisin (2007). However, common to all these conceptualizations is the explicit or implicit boundary between the outward- and inward-looking dimensions of absorptive capacity. While outward-looking absorptive capacity refers to the identification and acquisition of potentially useful knowledge from the environment, inward-looking capacity involves the assimilation and application of external knowledge (Cohen and Levinthal, 1990). In this paper, we focus specifically on the inward-looking dimensions of absorptive capacity, and consider outward-looking absorptive capacity as fixed.

Prior knowledge endowments are the main determinant of an organizations' absorptive capacity (Cohen and Levinthal, 1990). Although Cohen and Levinthal (1990) use R\&D investments empirically as a rough proxy for the firm's prior knowledge stock, they also developed a rich conceptualization of the distinct organizational mechanisms that influence the level of absorptive capacity. They argue that organizational absorptive capacity depends on the degree of connectedness among individuals and subunits within the organization. Cohen and Levinthal (1990: 132) posit that two determinants of inward-looking absorptive capacity are crucial: (1) the character and distribution of expertise available within the organization, and (2) the communication structure among the organization's agents. The combination of these dimensions allows organizations to understand and share relevant external and internal knowledge to increase their absorptive capacity. However, very few studies analyze how organizational-level mechanisms affect absorptive capacity (Volberda et al., 2010: 937).

Volberda et al. (2010: 936) state that: "most authors continue to frame their arguments in a very static way.... The study of AC in a dynamic way requires the use of longitudinal research methods...which allow investigating the pace and paths of change.” We respond by focusing on 
the hitherto rather unexplored dimension of absorptive capacity and its determinants, that of pace

— or, as we describe it, speed. We define absorption speed as the time it takes for the organization to assimilate and apply external knowledge in its own knowledge production.

Building on Cohen and Levinthal's insights on the roles of diverse expertise and the communication structure, this paper posits that the firm's ability to quickly absorb externally acquired knowledge into its own knowledge base depends on the firm's internal knowledge variety and coordinated transfer of knowledge. Internal knowledge variety provides access to a diverse set of problem-solving skills useful for absorbing external knowledge. To absorb external knowledge effectively, organizations also require coordinated knowledge transfer among internal subunits and individuals. We develop the argument that intrafirm network inventor task density enables tacit coordination of inventive activities, and consequently, subsequent communication between inventors with respect to problem-solving. Accordingly, network diversity and density in task relationship networks of inventors provide organizations with the required variety and coordination mechanisms to secure rapid absorption of external knowledge. Our theoretical construct and measure Intrafirm Inventor Task Network Diversity is most closely related to Carnabuci and Operti’s (2013) Knowledge Diversity measure. However, our measure includes only the collaborating inventors. Our Intrafirm Inventor Task Network Density construct and measure is aligned to Guler and Nerkar's (2012) Global Cohesion construct and to Howard, Steensma, Lyles and Dhanaraj's (2016) Innovation Network Density variable. However, Howard et al. use the density variable as a dependent variable, while the other two papers examine the direct effect of whole intrafirm networks on firm innovation performance, not absorption speed.

\section{Intrafirm inventor task relationship networks}

To integrate external technologies, companies need to be able to leverage intra-organizational 


\section{Knowledge Diversity and Coordination}

networks to transfer knowledge between relevant employees. In this paper, we study a particular sub-set of intraorganizational networks. Lincoln and Miller (1979: 182) note that "organizational research can hardly fail to maintain a distinction between instrumental ties, those arising in the course of performing appointed work roles, and primary ties, those informal social relations that have been shown to both enhance and impede the attainment of formal organizational goals.” There is a body of research on informal networks in the context of innovation that provides very important insights into the determinants of individuals' innovation performance (see for instance, Hargadon and Bechky, 2006; Tortoriello, 2015; Dahlander, O'Mahony, and Gann, 2016). However, our study builds on a different strand of the knowledge network literature that investigates formal inventor task networks (Nerkar and Paruchuri, 2005; Guler and Nerkar, 2012; Carnabuci and Operti, 2013) to explain the influence on firm-level absorptive capacity of instrumental ties within inventors' task collaboration networks. We view the characteristics of these specific intraorganizational networks as a major determinant of the firm's ability to quickly absorb externally acquired knowledge. In line with the literature on task relationship networks (for recent conceptualizations, see Casciaro and Lobo, 2015; Fonti and Maoret, 2016), we focus on a particular central task - in our case, the task of inventing. We posit that inventor networks can be considered networks of task relationships, involving "dyadic patterns of task interaction between organizational members” (Casciaro and Lobo, 2015: 373).

In our innovation context, R\&D scientists engage in inventive tasks that emphasize search and problem-solving (Fleming, 2001; Fleming and Sorenson, 2004; Laursen, 2012), within a network of intrafirm inventor task relationships. Inventor task networks are distinct from other types of networks because 1) each of the network nodes embeds state-of-the-art technical knowledge in specific technological fields which is particularly important for the integration of 
distant technological knowledge (Fleming, King III, and Juda, 2007), and 2) nodes are technologically specialized and diverse (Fleming et al., 2007), and therefore, based on the absorptive capacity argument, should be particularly relevant to the absorption process (Mowery, Oxley, and Silverman, 1996). In other words, the inventors in this type of network are able to provide one another with access to specialized and relevant technological knowledge (Nerkar and Paruchuri, 2005; Guler and Nerkar, 2012; Carnabuci and Operti, 2013; Grigoriou and Rothaermel, 2017) which favors external knowledge absorption. Finally, 3) co-inventor ties in inventor networks tend to be durable in their effect, even though interactions are likely to be less frequent than in informal networks. Indeed, inventors are likely to influence one another long after the coinvention experience. Singh (2005) reports significant information flow between patent coauthors, measured by citations in subsequent patents linked by direct and indirect collaborative ties. From a qualitative perspective, 13 of the 16 co-inventors interviewed by Fleming et al. (2007: 945) "reported some degree of technical interaction after a patent coauthorship.” We use these task network features as the basis for our subsequent theory development.

\section{HYPOTHESES}

\section{Technological distance and absorption speed}

This paper builds on a theoretically and empirically well-established baseline proposed in the absorptive capacity literature. Following Cohen and Levinthal (1990), we claim that firms that acquire technologically distant knowledge have limited prior related in-house knowledge. Those firms are faced with knowledge that is new to the firm which makes learning difficult. In a similar vein, Kogut and Zander (1992: 392) argue that "firms learn in areas closely related to their existing practice. As the firm moves away from its knowledge base, its probability of success converges to that for a start-up operation.” Indeed, the firm's knowledge stock allows it to make sense of the knowledge in the environment (Zahra and George, 2002; Rosenkopf and 


\section{Knowledge Diversity and Coordination}

Almeida, 2003). The assimilation of external knowledge requires a common understanding, or knowledge base overlap, in order to achieve successful application of that knowledge (Cohen and Levinthal, 1990; Mowery et al., 1996; Lane and Lubatkin, 1998; Gilsing et al., 2008). Thus, as the technological distance between the firm's knowledge base and the acquired external knowledge increases, the absorptive capacity of the firm declines which means that the integration of acquired external knowledge into an invention will require more effort and time, while technical problems are likely to arise in the case of unfamiliar knowledge.

Our baseline is corroborated empirically. Two recent empirical studies are particularly pertinent. Tzabbar et al. (2013) show that the rate of knowledge integration depends among other things, on the degree of familiarity with the knowledge transferred. Leone and Reichstein (2012) show that licensing-in accelerates firms' invention speed but that this effect decreases when firms in-license unfamiliar technologies. We aim to replicate recent prior studies, and expect that the greater the distance between the externally acquired knowledge and the firm's knowledge base, the longer it will take the firm to absorb the external knowledge into its own inventions.

\section{Source of variety: Intrafirm inventor task network diversity}

Task network diversity refers to the diversity of technical expertise available in the task relationship network among inventors (Reagans and McEvily, 2003; Harrison and Klein, 2007). In our context, it refers to the variety of relevant areas of technological expertise of the inventors collaborating on the inventive task within the firm. As pointed out above, each node in our inventor task network possesses state-of-the-art technical knowledge in a specific technological field; many of these inventor nodes differ from one another (Fleming et al., 2007). According to Cohen and Levinthal (1990), the diversity of knowledge available in the organization influences 
not only the outward-looking dimension of absorptive capacity but also the inward-looking dimension (our focus). Cohen and Levinthal (1990: 133) state that:

...there are benefits to diversity of knowledge structures across individuals that parallel the benefits to diversity of knowledge within individuals.... Assuming a sufficient level of knowledge overlap to ensure effective communication, interactions across individuals who each possess diverse and different knowledge structures will augment the organization's capacity for making novel linkages and associations-innovating-beyond what any one individual can achieve.

Clearly, if all the firm's inventors possess identical knowledge, there will be little scope for knowledge assimilation within the firm, whereas inventors with diverse expertise provide numerous opportunities for envisioning novel associations and linkages. Because of this rich set of in-house, readily available, diverse opportunities, we contend that an intrafirm task relationship network composed of a diverse group of inventors accelerates the speed of external knowledge absorption.

However, there are two reasons why an organization characterized by a diverse task relationship network is likely to be beneficial especially when it comes to assimilating distant knowledge. First, having the different expertise of multiple inventors available within the organization increases the prospect that the distant acquired external knowledge will be related to what is already known by some of the organizational members (Cohen and Levinthal, 1990; Mowery et al., 1996; Lane and Lubatkin, 1998). In other words, even in the case of external knowledge that is generally distant from the acquiring firm's knowledge base, the diversity among inventors in terms of state-of-the-art technical/inventive expertise increases the probability that there will be one or more individuals within the organization with at least some familiarity with the acquired knowledge. Second, having access to a diverse distribution of inventive expertise allows the organization to envision novel associations and relevant linkages to the acquired external knowledge. In this respect, Cohen and Levinthal (1990: 132) argue that 
"the group as a whole must have some level of relevant background knowledge, and when knowledge structures are highly differentiated, the requisite level of background [knowledge] may be rather high.” Indeed, having access to diverse approaches to problem-solving (Rodan and Galunic, 2004; Page, 2007) in the context of invention based on the disparate expertise of inventors within the organization, reduces the time needed to absorb distant knowledge acquired from outside the firm's boundaries.

However, as implied above, in the case of familiar external knowledge, intrafirm task network diversity should have a weaker effect compared to the case of distant knowledge. In the former case, inventor diversity is less crucial to absorption speed since the focal organization's (narrow) absorptive capacity is already high with respect to the particular externally acquired technology — the technology is already well understood. Similarly, in this case, there is also less need to create novel associations and relevant linkages to the acquired external knowledge which as already argued, are processes that are facilitated by intrafirm inventor task network diversity. In sum, we predict that:

Hypothesis 1. The more distant the external knowledge from the focal firm, the stronger the relationship between the level of intrafirm inventor task network diversity and the speed of absorption of the externally acquired knowledge into the firm's own inventions.

\section{Coordination: Intrafirm inventor task network density}

While diversity of expertise is important for external knowledge absorption, the absorptive capacity literature suggests that its absorption depends also on transfers of knowledge from one individual or subunit in the organization to another (Cohen and Levinthal, 1990). To ensure effective and speedy transfer of knowledge, organizations require internal structures that facilitate the flow of relevant information (Rodan and Galunic, 2004). We argue that a dense 


\section{Knowledge Diversity and Coordination}

intrafirm task inventor network can serve as an essential coordination device which allows for quicker assimilation of external knowledge and application of this knowledge in the focal firm's subsequent inventions. Srikanth and Puranam (2011: 850) argue that in a context characterized by tacit or specific knowledge distributed among a number of individuals, and complex interdependence of the knowledge held (such as the context of the invention process, see Pavitt, 1998; Sorenson, Rivkin, and Fleming, 2006), successful coordination is best achieved by either facilitating ongoing communication among the actors, or through tacit coordination by leveraging/building a stock of common knowledge. As pointed out above, co-inventors situated in a task network may not always be in frequent communication before the joint invention activity. Thus, ongoing communication among the actors may be a less relevant coordination mechanism in the case of the inventor task networks we consider in this paper. However, there is strong citation-based evidence suggesting that the task of co-invention has a persistent effect in the sense that inventors affect the future inventive activity of their co-inventors and have an effect on these co-inventor ties (Singh, 2005), and that co-inventors tend to some degree to engage in technical interaction after filing a joint patent (Fleming et al., 2007). These observations suggest that inventors are familiar with and knowledgeable about their coinventors’ inventive activities (and their relationship ties).

Srikanth and Puranam (2011: 850) state that tacit coordination is achieved when “interdependent individuals are able to coordinate their activities largely by relying on common ground-knowledge that is shared and known to be shared-formed by means other than ongoing communication.” In our context, tacit or implicit coordination is particularly relevant based on the idea that an intrafirm task inventor network allows its members to be informed about the specialisms of other inventors within the focal firm and what they are developing - 


\section{Knowledge Diversity and Coordination}

possession of such information facilitates speedy absorption. Dense (or cohesive or closed) networks are comprised of closely inter-connected members, and therefore allow for better tacit coordination. Indeed, many task relationship ties within organizations provide information and allow observation of potentially relevant inventors with the knowledge and skills needed to absorb distant external knowledge. Inventors with this type of shared knowledge emanating from dense networks can more easily, and therefore, more swiftly establish productive contacts and benefit from related knowledge transfer while minimizing redundant, costly, and timeconsuming knowledge transfer. Thus, dense networks tend to speed up the search for relevant information within the network (Zaheer and Bell, 2005), and to ease subsequent communication regarding joint problem-solving and the incorporation of externally acquired knowledge into firm-internal invention creation.

However, sparse networks also can enable firm innovation (Burt, 2004). A sparse network characterized by structural holes between clusters or sub-networks, can enhance firm innovation since such a network structure is likely to encompass diverse information and foster creativity (Tortoriello, 2015). Although sparse networks have been shown to be associated to high levels of heterogeneity which facilitate the creation of new knowledge, the absence of connections among network members reduces the speed with which individuals can share knowledge and access information (Singh, Hansen, and Podolny, 2010).

While there is reason to expect that dense intrafirm task inventor networks should allow for the coordination of inventive activities which in turn, should increase absorption speed in general, we posit also that inventor task network density should have a stronger effect in the case of distant external knowledge compared to familiar knowledge. Indeed, we argue that especially in relation to distant knowledge, ties are necessary to coordinate individuals and enable detection 
and exploitation of useful knowledge channels, and to exploit the experience and knowledge held by other inventors. In the case of familiar knowledge, (tacit) coordination among individuals is less essential since individual inventors are less reliant on their networks for solving the relatively easy problems related to familiar knowledge (Fleming et al., 2007). In sum, we hypothesize that: ${ }^{1}$

Hypothesis 2. The more distant the external knowledge from the focal firm, the stronger the relationship between the level of intrafirm inventor task network density and the speed of absorption of the externally acquired knowledge into the firm's own inventions.

\section{DATA AND METHODS}

The research sample is drawn from the global population of pharmaceutical firms. The choice of this industry as the setting for our study has several motivations. First, the pharmaceutical industry is characterized as technology-driven and $\mathrm{R} \& \mathrm{D}$ intensive, and is dependent on technological knowledge for developing and sustaining competitive advantage (Roberts, 1999). Second, pharmaceutical firms routinely and systematically protect and document their inventions by patenting (Levin et al., 1987) which allows us to rely on patent information to identify the technological profiles of the firms in our sample (Roberts, 1999). Third, the pharmaceutical industry has been proven to be a useful context to identify and measure the effect of inventor networks on innovative output (see e.g., Paruchuri, 2010).

Our dependent variable represents the speed of absorption of externally acquired

\footnotetext{
${ }^{1}$ Prior empirical studies show that network density has a positive impact on absorptive capacity. Tsai (2001) shows that in-degree centrality of business units positively influences innovation performance, and Jansen et al. (2005) find that connectedness among subunits has a positive influence on the transformation and exploitation stages of absorptive capacity. Moreover, Tzabbar et al. (2015) show that individual ego-network density improves knowledge transfer after a mobility event. However, none of this prior literature explains or tests empirically how task relationship whole network characteristics accelerate the absorption of distant external knowledge.
} 


\section{Knowledge Diversity and Coordination}

knowledge, measured as the time taken to apply an in-licensed technology to the focal firm's own new patents as evidenced by patent citations. This choice of dependent variable is based first on the fact that the firm's ability to capture returns from the external environment is a critical component of its absorptive capacity, making absorption speed a natural dependent variable in this context. Second, prior research highlights that firms that are able to innovate more quickly, achieve first-mover advantages and are able to capture new market opportunities (Markman, Gianiodis, Phan, and Balkin, 2005). Indeed, the (slow) generation of innovative solutions may prolong the time to new product introduction (Schoonhoven, Eisenhardt, and Lyman, 1990). Third, how quickly firms can internalize external knowledge is important since this is a source of competitive advantage, especially in industries where time-based competition is vital (Kessler and Chakrabathi, 1996; Leone and Reichstein, 2012; Tzabbar et al., 2013). One of the reasons why speed of absorption of external knowledge is important in the context of licensing-in is that it enables later entry into the product market after fundamental uncertainties have been resolved (Hawk, Pacheco-De-Almeida, and Yeung, 2013).

For several reasons, absorption speed matters in our particular context of the global pharmaceutical industry. Due to the effectiveness of patent protection in pharmaceuticals, and the exclusivity/protection granted by agencies such as the U.S. Food and Drug Administration, time is vital for pharmaceutical firms' competitiveness. Thus, being first can be of huge value (Roberts and Hauftman, 1987). R\&D races among pharmaceutical companies emphasize the importance of speed, for instance to obtain a first-in-class drug or a so-called follow-on drug, both of which can generate substantial revenue streams (Cockburn and Henderson, 1994; DiMasi and Faden, 2011). Furthermore, given the average length of the pharmaceutical drug discovery and development process — roughly ten years from conception to market (DiMasi, Hansen, and 


\section{Knowledge Diversity and Coordination}

Grabowski, 2003) — there would seem to be scope for speeding up the R\&D process (see also, Cardinal, 2001).

Four data sources were exploited for this study. First, we obtained detailed information on licensing agreements from the Deloitte Deal Builder Recap Database which covers licensing deals in the global pharmaceutical industry for the period 1983-2008. This database is one of the most accurate sources of information on pharmaceutical industry partnerships and technology exchanges (Schilling, 2009). Since it gives access to original licensing contracts involving patents it allows us to extract precise information on the date of the licensing event, characteristics of the licensed technologies, contractual specifications, and information enabling identification of licensees and licensors (e.g., firms' names and addresses, and operating segment). Second, we used patent data from the NBER project which allowed us to merge specific patent numbers linked to the traded technologies obtained from the Recap Database, with patents registered at the U.S Patent and Trademark Office (USPTO). NBER data were used also to identify the technological profiles of the firms in the sample. Third, the Harvard Patent Network Dataverse, provided us with disambiguated inventor names and inventor identification numbers. This allowed us to construct intrafirm inventor networks based on co-invention, and to derive inventor-level information. The fourth data source, the WRDS Compustat database, was exploited mainly to construct our control variables.

The final sample consists of 113 firms in the period 1986-2003 involving the acquisition of 708 USPTO patents through licensing contracts. ${ }^{2}$ This represents approximately 47 percent of the contracts registered at Recap that involved a patent transfer and initially were considered

\footnotetext{
2 This time-window was determined by information on inventors' patenting activity being available only from 1981 while the explanatory variables for intrafirm networks are calculated for a five-year period. Also, given that the firms in our sample take 26 months on average to absorb a licensed technology, we stopped the sample in 2003 to minimize right censoring concerns.
} 


\section{Knowledge Diversity and Coordination}

suitable to test our hypotheses. The observations excluded from the final analysis are mainly related to licensing contracts where we were unable to identify the licensee's name, or firms that do not publish their financial information. We also excluded contracts where the USPTO patent number connected to the licensed technology could not be identified. To minimize selection issues, we investigate the existence of systematic differences in terms of invention speed, related to observations where a patent number was identified in the contract, and observations where the patent number was not identified. Accordingly, we conduct a $t$-test comparing the number of months after the licensing date to licensees' first patent. The results indicate no statistically significant differences between the two groups.

\section{Dependent variable}

External Knowledge Absorption Speed. The time it takes firms to absorb a licensed technology is calculated using the number of months between the licensing date and the first time the licensee incorporated the licensed technology as a backward citation in a new patent. To be as close as possible to the date when the licensed technology was successfully absorbed, as a reference we use the date patent application rather than the patent granting date. Consequently, the date of external knowledge acquisition is defined on the basis of the licensing date specified in the Recap database, while data on absorption come from USPTO patent data. In order to model this dependent variable, we use a dummy variable that takes the value 1 if the licensed technology has been cited in a new patent and 0 otherwise.

\section{Explanatory variables}

We measure Technological Distance using the “focal index” proposed by Ziedonis (2007), i.e., the technology distance between a licensed technology and the firm's knowledge base is 
measured by the patent class connected to the licensed technology, and the technology classes in which the licensee was active prior to the licensing event. ${ }^{3}$ The measure is computed as:

$$
\text { Technological Distance }=1-\left[\frac{\left(\sum_{t-5}^{t} \sum_{j} \tilde{C}_{i} \cdot \rho_{i}\right)_{c}}{\left(\sum_{t-5}^{t} \sum_{j} \tilde{C}_{i} \cdot \rho_{i}\right)}\right]
$$

where $\left(\sum_{t-5}^{t} \sum_{j} \tilde{C}_{i} \cdot \rho_{i}\right)_{c}$ represents the citation-weighted sum of firm $i$ 's patents applied for within five years of the license agreement time $t$ and which belong to the same primary patent class $c$ as the licensed patent, and $\left(\sum_{t-5}^{t} \sum_{j} \tilde{C}_{i} \cdot \rho_{i}\right)$ is the sum of all citation-weighted patents issued to firm $j$ that were applied for by date $t$ during the same five-year time window. The use of weighted citations allows the relative importance of each patent in the firm's portfolio to be captured (Griliches, 1990). To correct for the fact that distance indexes based on patent classes can suffer from a downward bias (Aharonson and Schilling, 2016), we use a similar approach to the one proposed in Hall (2002) and apply the following correction terms to our measure $\times\left(\frac{N_{i t}}{N_{i t}-1}\right)$ where $N_{i t}$ captures the number of patents obtained by a firm i in the previous five years.

Intrafirm Inventor Task Network Diversity captures the distribution of technical knowledge across patent classes by inventors in the co-invention network of the focal firm (Rodan and Galunic, 2004). The first step to computing this measure is to identify which inventors were active when the technology was acquired (we consider as active those inventors with at least one patent application during the five years prior to the focal year). The way that our measure is computed takes account also of the effect of scientists’ mobility. If an inventor produced a patent at firm A and moved to our focal firm within the time window covered by our variable, the knowledge accumulated by that inventor in another firm will be part of the focal firm's available

${ }^{3}$ A limitation of this variable is that it does not account for possible uneven distribution of distance between some classes. However, we expect the effect of this limitation to be slight in our setting since we are interested in the relative distance between one patent class and the licensee's entire patent portfolio. 
technical expertise. If inventors move from the focal firm to another firm during the time window period covered by our variable, their knowledge does not contribute to the focal firm's knowledge expertise. Also, we examine diversity only among inventors with at least one active intrafirm tie. We define the level of network diversity in firm $i$ 's intra inventor network in year $t$ as:

$$
\text { Intrafirm Inventor Task Network Diversity }=1-\sum_{j=1}\left(\frac{N_{j i t}}{N_{i t}}\right)^{2}
$$

We consider that the primary class attributed to a patent reflects a distinct technology field $j=1$, 2, 3...th. Therefore, if the inventors within the ith firm accumulated $N_{i}$ patents during the five years prior to the licensing contract, each of the patents can be assigned to one technology field. Accordingly, $N_{i t}$ represents the total number of patents produced by the active inventors within firm $i$ in the previous five years, and $N_{j i t}$ is the number of patents assigned to technology class $j$ among the total number of patents produced by firm i's inventors.

We measure Intrafirm Inventor Task Network Density by calculating the overall density of the intrafirm network (Obstfeld, 2005; Ahuja, Soda, and Zaheer, 2011). Density captures the extent to which potential linkages within a network are realized, and is a commonly-used measure of network structure (Marsden, 1990; Guler and Nerkar, 2012). Network density for firm $i$ in year $t$ is computed as follows:

$$
\text { Intrafirm Inventor Task Network Density }=\frac{\text { Observed } N \text { inventor ties } \text { it }_{i t}}{\text { Possible } N \text { inventor } \text { ties }_{i t}}
$$

We define observed ties as the number of unique ties existing between two inventors that copatent, and the number of possible ties for the total number of inventors $\left(\frac{N \times(N-1)}{2}\right)$ listed in the firm's patents.

\section{Control variables}

To isolate the effects of the explanatory variables, we include several firm-, technology-, 


\section{Knowledge Diversity and Coordination}

contract-, and industry-level control variables which might affect the time it takes to absorb knowledge. We apply moving windows of different time lengths to compute these control variables. The time-windows range from four to seven years, and differ according to the specific control variable; the control variables for intrafirm network characteristics are calculated for the same length of time as the explanatory variables (5 years). In relation to intrafirm inventor network characteristics, we control for Average Tie Strength among the inventors in the focal firms, Clustering (Guler and Nerkar, 2012), and Average Path Length (Fleming et al., 2007), three structural characteristics that we would expect to affect knowledge flows across inventors by speeding up the time taken to transfer knowledge between two points in the network.

For acquiring firm characteristics, we control for firm $R \& D$ intensity as total $\mathrm{R} \& \mathrm{D}$ expenditure divided by total sales at year $t$. We also include a dummy variable (Previous Year) which takes the value 1 if the firm produced a patent during the year prior to the license date. We use this variable to control for the fact that firms may vary in how often they patent. Another characteristic that can influence the rate at which the licensee is able to absorb external knowledge and to speed up its absorption is familiarity with the licensor's technologies other than the licensed technology. Therefore, we control for the total number of the licensee's Prior Citations to the licensor's other patents during the four years prior to the licensing contract. Additionally, we include a dummy variable (Co-patent) which captures the number of successful patents produced jointly by the focal firm and other firms within the three years prior to the licensing date. This variable captures the existence of inter-firm ties that allow inventors to acquire relevant knowledge. Given that the geographical dispersion of inventors also is expected to affect intrafirm networks and knowledge flows, using a Herfindahl index we apply a measure similar to that in Hannigan, Cano-Kollmann and Mudambi (2015) to capture the Geographical 


\section{Knowledge Diversity and Coordination}

Dispersion of Inventors across countries. The variable reflects a central part of the formal structure and organization of R\&D within the firms (Argyres and Silverman, 2004) which is very relevant in the case of speed of absorption of external knowledge. Specifically, the idea is that if inventors are geographically dispersed within the firm, this is a strong indication that $\mathrm{R} \& \mathrm{D}$ is decentralized. Because star scientists have been shown to affect firms' innovation output (Grigoriou and Rothaermel, 2017), we control also for the firm's Number of Star Scientists using a similar approach to that in Kehoe and Tzabbar (2014). As a first step, we compute the total number of patents produced by each individual inventor in the sample applied for by year $t$. Next, we divide the total number of patents by inventor tenure at year $t$, measured as the number of years since the scientist first patented. Then we multiply the measure by the average number of forward citations received by the patents produced by the scientist each year. Based on this composite variable, we can identify as star scientists individuals with a value at least two standard deviations above the industry mean value in a given year $t$. Finally, we count the total number of star inventors in firm $i$ at year $t$.

To control for firm size, we include the logarithm of the number of employees in the year of the licensing deal. We control also for the amount of unabsorbed resources using licensee Slack, calculated as the ratio of number of employees to sales (Mellahi and Wilkinson, 2010). Finally, we include a dummy variable which takes the value 1 if the licensee is headquartered in the U.S. (US Firm). We use a group of dummy variables to control for licensing deal contractual specifications. A Technological Furnishing clause commits the licensor to supplying know-how about the licensed technology to support its understanding and application by the licensee, thus mitigating some of the problems related to distance. This implies that in contracts that include this clause, the licensor agrees to provide additional support to the licensee related to how to use 


\section{Knowledge Diversity and Coordination}

the licensed technology. Another important control variable is Grant-back Clause. The inclusion of a grant-back clause in a contract gives the licensor rights to any improvements to the licensed technology developed by the licensee (Choi, 2002). These two contractual clauses are relevant also to control for variations in the extent to which licensors may be less inclined to share knowledge due to concerns regarding holdup and opportunistic behavior after the licensing deal (Laursen, Moreira, Reichstein, and Leone, 2017). We expect the inclusion of those clauses to reduce the risk to the licensor of opportunistic behavior by the licensee, making the former more willing to commit to ex-post knowledge transfer (Choi, 2002). Finally, we control for a Milestone payment clause in the licensing contract. In terms of technology related characteristics, it is important to account for the effect of the stage of development of the technology at licensing on the speed of knowledge absorption. Based on Recap information, we created a dummy variable called Early Stage Technology which takes the value 1 if the drugs were licensed before the clinical stage, and zero otherwise (Banerjee, 2012). We control also for Technology Value using the total number of forward citations received by the licensed technology

We control for licensors’ characteristics first by accounting for differences between firms and universities as licensors by including a dummy variable for the licensor being a university (Licensor University). Second, we control for the Number of (successful) Patent applications filed by the licensor in the seven years prior to the licensing contract, to account for differences in the size and technological capabilities of the licensor. We constructed a set of controls for the effect of industry and market competition on the speed of external knowledge absorption. To account for those effects, we compute the variable Industry Competition based on a Herfindahl index, using the sales of all firms operating within the same four-digit SIC code of the licensee in the given year. This measure has been used extensively in previous studies (e.g., Lang and Stulz, 


\section{Knowledge Diversity and Coordination}

1992; Hou and Robinson, 2006) to capture the effect of product market competition on several dimensions of firm behavior. We account also for growth in the firms' main market share based on the relative changes in total sales in the licensee's four-digit SIC code between $t-1$ and $t$ (Market Growth).

Finally, we use two sets of dummies to capture differences in the technological fields of the licensed technologies and the operating segments of the licensees in our sample. First, we rely on the classification proposed by the World Health Organization and the description provided in Recap to create dummy variables to account for differences in 12 main therapeutic areas plus miscellaneous, observed across the licensing deals. ${ }^{4}$ Second, on the basis of the Recap database, we classify the firms in the final sample according to three main sectors: Biotech, Pharmaceutical, and Medical devices. To capture cross-sector differences in innovation speed, we use sector fixed effects based on dummy variables for the licensees' main operating segment.

\section{Model specification and estimation}

Since our hypotheses refer to the time taken to absorb knowledge, we generated a dependent variable based on an event history analysis structure. Using a survival model to investigate the effect of the explanatory variables on the time it takes to successfully absorb external knowledge has at least two major advantages. First, this technique allows us to measure the dependent variable (time) in months rather than measuring it discretely using dummies. Second, it allows us to model observations that do not experience the transition (absorption) during the time frame covered by the data, by considering right-censoring issues as a non-random process (Blossfeld,

\footnotetext{
${ }^{4}$ The licensed technologies were classified according to the following therapeutic areas: Alimentary Tract and Metabolism, Blood and Blood Forming Organs, Cardiovascular System, Dermatologicals, Genito Urinary System and Sex Hormones, Systemic Hormonal Preparations, Anti-infectives for Systemic Use, Antineoplastic and Immunomodulating Agents, Musculoskeletal System, Nervous System, Respiratory System, Sensory Organs, and Miscellaneous.
} 


\section{Knowledge Diversity and Coordination}

Golsch, and Rohwer, 2007), and including observations for which we have only partial information on the time they entered the sample (licensing date) to the last date that patent data on backward citations are available. Following previous studies (e.g., Leone and Reichstein, 2012), we employ a log-logistic specification to accommodate the time-dependence shape of the transition rate for the observations in the sample.

\section{Descriptive statistics and correlations}

Table 1 reports the means, standard deviations, and Pearson correlation coefficients of the variables used in the analysis. Except for the correlations between Average Path Length and Intrafirm Inventor Task Network Density, and Clustering and Average Tie Strength, these results raise no variable collinearity concerns. The correlations between Average Path Length and Intrafirm Inventor Task Network Density, and Clustering and Average Tie Strength are in line with the theoretical expectations but in order to check for potential bias, the variables are entered stepwise in the econometric models. The results for the main explanatory variables do not change as the variables enter the model.

[Insert Table 1 around here]

We track the patenting behavior of the firms in our sample up to December 2006; therefore, our analysis is censored at the latest dates available in the patent citations data. Considering knowledge absorption speed from a descriptive perspective, the longest time to transition for the firms in our sample is 168 months. Among the 708 firm-technology observations, a total of 116 firms cite the licensed technology in a new patent (i.e., absorption achieved) during the time frame of our analysis. For the observations that experienced transition, the average time for successful knowledge absorption is 25 months. This can be compared with the average at risk time of 74 months for all the firms in the sample (including censored 


\section{Knowledge Diversity and Coordination}

observations). Among the 592 firm-technology observations that did not experience transition during the time window of our analysis, 129 observations exited the sample before December 2006. These observations are subject to a different type of right-censoring. In our empirical setting, they exit the sample early because they disappear from Compustat (through bankruptcy or acquisition) and end earlier than the latest information available in the patent data. We model those observations by setting the exit time to the date of the latest Compustat record.

We plot the cumulative hazard function after estimating the log-logistic model, to visualize the pattern of the hazard function. The graphs (see Figure 1) indicate that the transition rate first rises monotonically and then falls monotonically. ${ }^{5}$ Additionally, to visualize the shape of the hazard rate for observations with high and low levels of technological distance, we generate two groups using the mean values for distance. As Figure 1 suggests, firms dealing with lower distance values have a higher probability of experiencing earlier transition compared to those firms coping with high distance levels. This pattern provides initial support for the ideas tested in relation to our baseline, regarding the effect of distance on the speed of external knowledge absorption.

[Insert Figure 1 around here]

\section{Endogeneity and selection}

To include firm-specific unobserved heterogeneity, our log-logistic model is estimated using a shared frailty model with gamma mixture specification (Blossfeld et al., 2007). This is important as we need to account for unobserved idiosyncratic organizational characteristics-beyond our control variables—such as those related to R\&D structure and internal governance. A second potential source of endogeneity concerns the selection of technologies by licensees which takes

\footnotetext{
${ }^{5}$ Our decision to use a log-logistic specification was guided by the statement in Blossfeld et al. (2007: 204) that "in the literature, the log-logistic model along with log-normal and the Sickle distributions are the most commonly recommended models if the transition rate is somehow bell-shaped”.
} 


\section{Knowledge Diversity and Coordination}

place before the licensing deals observed in our sample. Although it might be expected that the individuals that decide about which technologies to license would have limited control over the configuration of inventor networks, it is possible that the probability that a patent is licensed may be affected by the unobserved characteristics of the invention itself, and that these differences are somehow related to our explanatory variables (Nerkar and Shane, 2007). To deal with this issue, we follow Nerkar and Shane (2007), and as part of our empirical strategy implement a two-stage selection model in which the first stage accounts for the likelihood of licensee $i$ licensing-in technology $j$ at a given point in time. We base the first stage on a pool of licensable technologies patented by the licensor around the same time as the technologies observed in our sample. Next, we estimate a model in which this pool of technologies is at "risk" of being licensed by the licensees in our sample, where onset of risk is the patent filing date, and transition is the date of the licensing agreement. Based on these estimates, we compute the cumulative hazard function and the standard normal density to create a selection correction variable which is used in our main model (for more details on this procedure, see Nerkar and Shane, 2007).

Some characteristics of licensed-in technologies not observed in non-licensed technologies (e.g., contractual clauses) cannot be included as controls in this estimation but are used in a subsequent model without the selection correction term. To make the selection correction variable credible, we use degree of technological specialization of the licensor firm as an exclusion restriction. Specialized licensors are less likely to have complementary downstream assets to exploit a technology in the product market, and therefore, are pushed to make licensingout decisions sooner (Mowery, 2009). We expect that the decision to enter a licensing deal for a specific technology depends on both licensor and licensee but the decision to absorb knowledge is confined to the latter. The results of the estimators with and without the selection correction 


\section{Knowledge Diversity and Coordination}

terms are reported in Table 2.

\section{RESULTS}

\section{Speed of knowledge absorption}

We start by reporting the results for the log-logistic model with the shared gamma mixture specification without the selection correction terms (see Table 2, Models I-V). Model I reports the estimations for the controls and the variables underlying the interaction terms. In Model II, we first enter the variable for technological distance in order to test our baseline. Models III and IV include the interaction terms capturing the relationships described in the hypotheses, and also the controls. To test how the interaction between Intrafirm Inventor Task Network Density $\times$ Log (Number Employees) might affect our explanatory variables, we include this interaction term when estimating Models V and VI. We expect that this interaction will capture any effect of licensee size affecting the speed of knowledge absorption through Intrafirm Inventor Task Network Density. Model VI includes a selection correction term, and therefore deals explicitly with endogeneity concerns arising from the potential selection of licensed technologies that took place before the licensing deals are observed. It can be seen that the direction and significance of the coefficients of this model are comparable to Model V (without the selection correction term). Therefore, it is unlikely that our results are being driven by the above described selection issues.

[Insert Table 2 around here]

We find a positive and statistically significant coefficient of Technological Distance (pvalue $=0.013$ ). This offers support for the idea that the greater the distance between the externally acquired knowledge and the firm's knowledge base, the longer it will take the firm to absorb the external knowledge into its own inventions. This is in line with the findings in Tzabbar et al. 


\section{Knowledge Diversity and Coordination}

(2013) and Leone and Reichstein (2012), who find that distance is an important predictor of the firm’s capacity to absorb external knowledge rapidly.

The main effects for our main intrafirm collaboration network variables Intrafirm Inventor Task Network Diversity and Intrafirm Inventor Task Network Density are both negative and statistically significant in Models III and IV, indicating that these variables affect absorption speed for average levels of Technological Distance. More importantly for our hypotheses, the coefficient of the interaction between Technological Distance and Intrafirm Inventor Task Network Diversity is negative and significant ( $p$-value=0.000), supporting the idea that network diversity negatively moderates the relationship between distance and the time it takes to absorb knowledge, i.e., it speeds up the absorption of distant knowledge. This supports Hypothesis 1. In addition, the coefficient of the interaction term between Technological Distance and Intrafirm Inventor Task Network Density is negative and significant ( $p$-value=0.017), indicating that the positive effect of distance on the time it takes to absorb knowledge becomes less positive (or more negative) when interacted with network density. This supports the moderating effect predicted in Hypothesis 2.

To interpret the effect sizes of the relevant estimated coefficients, we estimate the response margins at the mean values of our variables of interest for the uncensored observations in our sample. The results indicate that when Technological Distance increases by one standard deviation from its mean, the time to external knowledge absorption increases by 12 months ( $p$ value $=0.031$ ). Next, we examine how the direct effect of distance on time to knowledge absorption changes conditional on different levels of our two moderator variables. We observe that when Intrafirm Inventor Task Network Diversity increases by one standard deviation from its mean, the average effect of distance on time to external knowledge absorption decreases by 
some 10 months (p-value=0.069). A similar effect is observed for Intrafirm Inventor Task Network Density where an increase of one standard deviation from the mean leads to a reduction of the order of 17 months in the average effect of distance on the values of our dependent variable $(p$-value $=0.056)$.

\section{ALTERNATIVE EXPLANATIONS AND ROBUSTNESS CHECKS}

A concern related to the data structure used to conduct our empirical analyses is that we use time-invariant explanatory variables. We adopted this set-up for two main reasons. First, the average time to citation of a licensed-in technology is 25 months, and we observe that the firm network characteristics for our sample are very stable. ${ }^{6}$ Second, at the theoretical level, it could be argued that what matters is the absorptive capacity of the inventor network organization at the onset of risk-any subsequent changes in the networks may be largely endogenous.

Despite these potential limitations, observing how time varying explanatory variables affect the speed of knowledge absorption within a longitudinal setting allows a dynamic perspective which complements our main analysis. It is possible that networks and other firm related characteristics that change after the licensing deal might be affecting our results. To test for this, we construct a panel with time-varying explanatory variables using time of the licensing event as the time of onset of risk, and date of citation as the time of transition for non-censored observations. This additional test is reported in Models I, II, and III in Table 3 and shows that the results are consistent with our main econometric estimations reported in Table 2.

The applied shared frailty estimator with a gamma mixture specification helps to address some potential concerns regarding unobserved (firm-level) heterogeneity. However, given that the shared frailty estimator is a random effects model to the extent that the unobserved

\footnotetext{
${ }^{6}$ The correlations between Intrafirm Inventor Task Network Diversity, Intrafirm Inventor Task Network Density, Average Tie Strength, Clustering and Average Path Length at time $t$ and $t-1$ are all above 0.75, suggesting high stability.
} 


\section{Knowledge Diversity and Coordination}

heterogeneity is correlated to the observed explanatory variables, there might be some unaccounted for unobserved heterogeneity. One limitation of hazard models is that "real" fixed effects estimators are not available. To address this issue, as a robustness check we include the equivalent of firm fixed effects by adding firm dummies to the log-logistic hazard model. Because the firm dummies tend to be highly correlated to the other controls in our sample, we estimate this robustness check in an unrestricted version of the original model. Table 3 reports Models IV, V, and VI which include the firm dummies. The main results are largely unchanged compared to the original model, lending further support to the notion that unobserved firm-level heterogeneity coming from time invariant characteristics is not biasing our results.

[Insert Table 3 around here]

We conducted four additional robustness checks (results not reported here for space reasons). First, the network literature points to the potential downsides of very high levels of network diversity and density. This suggests that diversity and density might moderate the effect of distance on time to knowledge absorption according to an inverted $U$ shape. We investigate this empirically by adding to Model V (Table 2) the squared values of our measures for network density and network diversity, and their respective interactions with technological distance. The parameters of the relevant squared variables are statistically insignificant. The results are also insignificant for the squared terms when the interaction terms are excluded. Second, another explanation for the effect of distance on time to knowledge absorption is related to the fact that distant technologies may not be licensed with the intention of applying them in a new invention. To address this, we conducted a $t$-test comparing the distance between those observations that experience transition and are cited in a new in-house patent during the time window of our analysis, and those that are not. We found no statistically significant difference between the two 
groups. We also investigated if our results are affected by differences in the windows used to compute our network measures. The results obtained using a four and six-year windows are consistent with those presented in the paper.

\section{DISCUSSION AND CONCLUSION}

We began by noting that the theoretical and empirical literature suggests that firms' absorption speed decreases with the degree of unfamiliarity of the external knowledge. We employed an absorptive capacity and inventor task networks lens to propose that firms with whole inventor task networks with appropriate characteristics pertaining to a within-network variety of knowledge and to the support of the coordination of inventive activities among inventors are able to increase their speed of absorption of external knowledge.

This study has important theoretical implications. An important contribution is that it adds an intrafirm inventor task network dimension to the external knowledge sourcing literature. This body of work tends to focus on the relations between the firm and its external sources of innovation, and ignores how intrafirm organizational factors support the exploitation of external knowledge for innovation. We contribute by explicitly considering organizational factors in terms of intrafirm task inventor networks. Since Burns and Stalker (1961), it has been recognized that the firm's internal organizational relationships matter for innovation outcomes. However, subsequent related work on intrafirm task inventor networks (e.g., Guler and Nerkar, 2012; Carnabuci and Operti, 2013) has tended to focus on how internal task inventor networks affect the recombination of in-house knowledge for the purposes of innovation but does not consider how they might facilitate the exploitation of external knowledge at firm level.

This study adds to work in the absorptive capacity literature by specifying a set of micro mechanisms that underlie firms' inward-looking absorptive capacity, including firm-internal sources of knowledge variety, and coordination of knowledge-intensive activities to avoid 


\section{Knowledge Diversity and Coordination}

wasteful action. We have proposed a set of theoretical mechanisms that build on Cohen and Levinthal's seminal 1990 paper, to explain how intrafirm inventor networks fulfill those two tasks, and ensure rapid absorption of (in particular) distant external knowledge into the focal firms' inventions. These mechanisms also explain why diversity provides the variety of knowledge needed for innovation, and why network density acts as the necessary coordination device. This increases theoretical understanding of the process of knowledge absorption, and operationalizes absorptive capacity in terms of absorption speed and its antecedents empirically in the important context of invention. We found empirical support for our predictions: intrafirm inventor task network diversity and inventor task network density positively moderate the relationship between degree of distance between the focal firm's knowledge base and externally acquired knowledge, and speed of absorption of external knowledge into the focal firm's knowledge production for invention output.

Our theoretical arguments and empirical findings also relate to time compression diseconomies in R\&D (Scherer, 1967; Dierickx and Cool, 1989; Pacheco-de-Almeida and Zemsky, 2007) insofar as they refer to the integration of internal and external knowledge components. In the literature, these time compression diseconomies are taken as exogenously given due to the nature of the R\&D process, and imply that while it is possible to speed up the completion of an innovation project by hiring more people to complete each of the tasks involved, overall development costs will increase due to the onset of classical diminishing returns (Scherer, 1967). We show that heterogeneity in the characteristics of the firms' inventor task networks, and therefore, heterogeneity in inward-looking absorptive capacity, drive variation in invention speed, especially when distant knowledge is involved. This suggests in turn, that inward-looking absorptive capacity reduces "the costs of speed" for the focal firm. In 


\section{Knowledge Diversity and Coordination}

other words, an appropriate task network set-up of innovation professionals can increase this speed compared to other organizations, regardless of time compression diseconomies.

The findings in this paper have implications for managerial practice. They point to the influence of intrafirm task network structure on the ability of firms to integrate external knowledge quickly. Managers should pay attention to the collaborative behavior of their employees; although managers cannot directly control their employees' collaborative interactions with other employees, they can assign inventors to temporary projects to foster collaboration among otherwise unconnected employees. Managers need to support the inventor network structures in $\mathrm{R} \& \mathrm{D}$ departments to encourage a culture of continuous effective knowledge sharing and knowledge transfer among inventors and research units.

This paper has some limitations. First, although we took care over the design of the empirical research, endogeneity problems might still be an issue; however, we believe that the empirical strategy employed reduces concerns over unobserved heterogeneity and omitted variables bias. We employed a frailty estimator in our hazard models to capture unobserved heterogeneity through the inclusion of a shared gamma mixture specification. As robustness checks, we included firm dummies to pick up additional possible unobserved heterogeneity, and applied a two-stage model to account for the possibility that the in-licensed patents are of a particular type. Although our findings should be generalizable to other high-technology sectors such as telecommunications, consumer electronics, and computers, future research would confirm whether our proposed theory is transferable to other industries. We focus specifically on the role of whole firm-level networks composed of intrafirm task inventor ties for affecting absorption speed. However, individual inventors' ties across firm boundaries may also have an impact on the firm's ability to recombine external and internal knowledge (Tushman and 


\section{Knowledge Diversity and Coordination}

Scanlan, 1981; Tortoriello and Krackhardt, 2010). Future research could investigate these external individual ties.

The composition of the inventor team that produced the patent first citing an acquired patent might also matter for absorption speed. For instance, the team might include a "generalist" (Melero and Palomeras, 2015) or a "relational star” (Grigoriou and Rothaermel, 2014). We can speculate that because a generalist inventor plays a knowledge bridging function which could be particularly important for knowledge absorption (Melero and Palomeras, 2015), the presence of a generalist on an inventor team could help speed up knowledge absorption by enabling better utilization of diverse technical expertise within the focal team (and perhaps beyond it). Similarly, a relational star on the inventor team potentially might contribute to the coordination of inventive activities in parallel to the effect we have suggested for our intrafirm network density variable, which effect in turn, might also increase absorption speed. Unfortunately, our research design does not allow us to include inventor team characteristics in our empirical models. While we do not expect these team characteristics to be critically correlated to our central independent variables (and we control for the number of star scientists in the inventor network), the importance of inventor team composition for knowledge absorption speed should be investigated in future research.

In line with the intra-organizational networks literature, we utilize co-patenting to capture inventor task networks (Singh, 2005; Fleming et al., 2007; Paruchuri, 2010). We acknowledge that co-patenting captures only a subset of the interpersonal ties within a firm, although our focus on inventor networks appears particularly relevant in the context of firms' absorptive capacity and distant external knowledge. Future work could examine other types of interpersonal ties. In addition to the organization's (formal/instrumental) inventor task networks (e.g., the present 
paper, Guler and Nerkar, 2012; Carnabuci and Operti, 2013), the literature on organization as a determinant of knowledge absorption also investigates the role of intraorganizational informal advice innovation networks (e.g., Tortoriello, 2015; Dahlander et al., 2016). We can speculate that such informal advice networks will also have the properties that would allow increased speed of knowledge absorption. However, given that previous research shows that the positive effects of external knowledge on individual-level innovation generation are reinforced if the individuals sourcing the external knowledge span structural holes in the internal knowledgesharing network (Tortoriello, 2015), we would expect informal networks to work particularly well if they include (many) individuals who span structural holes. However, the two types of formal and informal innovation networks might be complementary, due possibly to the smallworld characteristics that combined networks potentially exhibit (cf. Fleming et al., 2007). These are issues that require empirical scrutiny in future research. We hope nevertheless that the present paper constitutes a first step towards further investigation of this exciting research agenda.

\section{ACKNOWLEDGEMENTS}

This article has benefited greatly from the guidance provided by the Editor, Anita McGahan, and four anonymous reviewers. The authors are grateful also for comments on earlier versions of the paper from seminar audiences at Boston University, BI Oslo, KU Leuven, Utrecht University, IE Business School, Nova School of Business and Economics, University of Bath School of Management, IESE Business School, SKEMA Business School, and participants in the Academy of Management Conference, the DRUID Summer Conference, the Gothenburg Workshop Evolutionary Approaches to Entrepreneurship and Regional Development, the Boston College AoM TIM Midyear Meeting, the Cass Business School Workshop on Scale and Scope, and the DTU-TIE Conference. The usual caveats apply. Keld Laursen's Professor II position at NTNU is sponsored by DNV-GL. 


\section{REFERENCES}

Aharonson BS, Schilling MA. 2016. Mapping the Technological Landscape: Measuring Technology Distance, Technological Footprints, and Technology Evolution. Research Policy 45(1): 81-96.

Ahuja G, Soda G, Zaheer A. 2011. The Genesis and Dynamics of Organizational Networks. Organization Science 23(2): 434-448.

Argyres NS, Silverman BS. 2004. R\&D, Organization Structure, and the Development of Corporate Technological Knowledge. Strategic Management Journal 25(8-9): 929 - 958.

Banerjee T. 2012. Aspects of Research and Development Contract Terms in the Bio/Pharmaceutical Sector, In the Economics of Medical Technology: 1-33: Published online.

Blossfeld H-P, Golsch K, Rohwer G. 2007. Event History Analysis with Stata. Lawrence Erlbaum Associates Publishers: Mahwah, NJ US.

Bridoux F, Smith KG, Grimm CM. 2011. The Management of Resources. Journal of Management 39(4): 928-957.

Burns T, Stalker GM. 1961. The Management of Innovation. Tavistock: London.

Burt RS. 2004. Structural Holes and Good Ideas. American Journal of Sociology 110(2): 349-399.

Cardinal LB. 2001. Technological Innovation in the Pharmaceutical Industry: The Use of Organizational Control in Managing Research and Development. Organization Science 12(1): 19-36.

Carnabuci G, Operti E. 2013. Where Do Firms' Recombinant Capabilities Come From? IntraOrganizational Networks, Knowledge, and Firms' Ability to Innovate through Technological Recombination. Strategic Management Journal 34(13): 1591-1613.

Casciaro T, Lobo MS. 2015. Affective Primacy in Intraorganizational Task Networks. Organization Science 26(2): 373-389.

Choi JP. 2002. A Dynamic Analysis of Licensing: The "Boomerang" Effect and Grant-Back Clauses. International Economic Review 43(3): 803-829.

Cockburn I, Henderson R. 1994. Racing to Invest? The Dynamics of Competition in Ethical Drug Discovery. Journal of Economics and Management Strategy 3

Cohen WM, Levinthal DA. 1990. Absorptive Capacity : A New Perspective on Innovation and Learning. Administrative Science Quarterly 35(1): 128-152.

Dahlander L, O'Mahony S, Gann DM. 2016. One Foot in, One Foot Out: How Does Individuals' External Search Breadth Affect Innovation Outcomes? Strategic Management Journal 37(2): 280-302.

Dierickx I, Cool K. 1989. Asset Stock Accumulation and Sustainability of Competitive Advantage. Management Science 35(12): 1504-1511.

DiMasi JA, Faden LB. 2011. Competitiveness in Follow-on Drug R\&D: A Race or Imitation? Nature reviews. Drug discovery 10: 23-27.

DiMasi JA, Hansen RW, Grabowski HG. 2003. The Price of Innovation: New Estimates of Drug Development Costs. Journal of Health Economics 22: 151-185.

Fleming L. 2001. Recombinant Uncertainty in Technological Search. Management Science 47(1): 117-132.

Fleming L, King III C, Juda AI. 2007. Small Worlds and Regional Innovation. Organization Science 18(6): 938-954.

Fleming L, Sorenson O. 2004. Science as a Map in Technological Search. Strategic Management Journal 25(8/9): 909-928.

Fonti F, Maoret M. 2016. The Direct and Indirect Effects of Core and Peripheral Social Capital on Organizational Performance. Strategic Management Journal 37(8): 1765-1786.

Foss NJ, Laursen K, Pedersen T. 2011. Linking Customer Interaction and Innovation: The Mediating Role of New Organizational Practices. Organization Science 22(4): 980-999. 
George JM, Jones GR. 2000. The Role of Time in Theory and Theory Building. Journal of Management 26(4): 657-684.

Gilsing V, Nooteboom B, Vanhaverbeke W, Duysters G, Vandenoord A. 2008. Network Embeddedness and the Exploration of Novel Technologies: Technological Distance, Betweenness Centrality and Density. Research Policy 37(10): 1717-1731.

Grigoriou K, Rothaermel FT. 2014. Structural Microfoundations of Innovation: The Role of Relational Stars. Journal of Management 40(2): 586-615.

Grigoriou K, Rothaermel FT. 2017. Organizing for Knowledge Generation: Internal Knowledge Networks and the Contingent Effect of External Knowledge Sourcing. Strategic Management Journal 38(2): 395-414.

Griliches Z. 1990. Patent Statistics as Economic Indicators: A Survey. Journal of Economic Literature 28(4): 1661-1707.

Guler I, Nerkar A. 2012. The Impact of Global and Local Cohesion on Innovation in the Pharmaceutical Industry. Strategic Management Journal 33(5): 535-549.

Hall BH. 2002. A Note on the Bias in the Herfindahl Based on Count Data. In A Jaffe, M Trajtenberg (Eds.), Patents, Citations, and Innovation: 149-156. MIT Press: Cambridge, MA.

Hannigan TJ, Cano-Kollmann M, Mudambi R. 2015. Thriving Innovation Amidst Manufacturing Decline: The Detroit Auto Cluster and the Resilience of Local Knowledge Production. Industrial and Corporate Change 24(3): 613-634.

Hargadon AB, Bechky BA. 2006. When Collections of Creatives Become Creative Collectives: A Field Study of Problem Solving at Work. Organization Science 17(4): 484-500.

Harrison DA, Klein KJ. 2007. What's the Difference? Diversity Constructs as Separation, Variety, or Disparity in Organizations. Academy of Management Review 32(4): 1199-1228.

Hawk A, Pacheco-De-Almeida G, Yeung B. 2013. Fast-Mover Advantages: Speed Capabilities and Entry into the Emerging Submarket of Atlantic Basin Lng. Strategic Management Journal 34(13): 1531-1550.

Hou K, Robinson DT. 2006. Industry Concentration and Average Stock Returns. The Journal of Finance 61(4): 1927-1956.

Howard M, Steensma HK, Lyles M, Dhanaraj C. 2016. Learning to Collaborate through Collaboration: How Allying with Expert Firms Influences Collaborative Innovation within Novice Firms. Strategic Management Journal 37(10): 2092-2103.

Jansen JJP, van den Bosch FAJ, Volberda HW. 2005. Managing Potential and Realized Absorptive Capacity: How Do Organizational Antecedents Matter? Academy of Management Journal 48(6): 999-1015.

Kessler EH, Chakrabathi AK. 1996. Innovation Speed: A Conceptual Model of Context, Antecedents, and Outcomes. The Academy of Management Review 21(4): 1143-1191.

Kogut B, Zander U. 1992. Knowledge of the Firm, Combinative Capabilities, and the Replication of Technology. Organization Science 3(3): 383-397.

Lane PJ, Lubatkin M. 1998. Relative Absorptive Capacity and Interorganizational Learning. Strategic Management Journal 19(5): 461-477.

Lang LHP, Stulz R. 1992. Contagion and Competitive Intra-Industry Effects of Bankruptcy Announcements. Journal of Financial Economics 32(1): 45-60.

Laursen K. 2012. Keep Searching and You'll Find: What Do We Know About Variety Creation through Firms' Search Activities for Innovation? Industrial and Corporate Change 21(5): 1181-1220.

Laursen K, Moreira S, Reichstein T, Leone MI. 2017. Evading the Boomerang Effect: Using the Grant-Back Clause to Further Generative Appropriability from Technology Licensing Deals. Organization Science 28(3): 514-530. 
Leone MI, Reichstein T. 2012. Licensing-in Fosters Rapid Invention! The Effect of the Grant-Back Clause and Technological Unfamiliarity. Strategic Management Journal 33(8): 965-985.

Levin RC, Klevorick AK, Nelson RR, Winter SG, Gilbert R, Griliches Z. 1987. Appropriating the Returns from Industrial Research and Development. Brookings Papers on Economic Activity(3): 783-831.

Lincoln JR, Miller J. 1979. Work and Friendship Ties in Organizations: A Comparative Analysis of Relation Networks. Administrative Science Quarterly 24(2): 181-199.

Macher JT, Boerner CS. 2006. Experience and Scale and Scope Economies: Trade-Offs and Performance in Development. Strategic Management Journal 27(9): 845-865.

Markman GD, Gianiodis PT, Phan PH, Balkin DB. 2005. Innovation Speed: Transferring University Technology to Market. Research Policy 34(7): 1058-1075.

Marsden PV. 1990. Network Data and Measurement. Annual Review of Sociology 16: 435-463.

Melero E, Palomeras N. 2015. The Renaissance Man Is Not Dead! The Role of Generalists in Teams of Inventors. Research Policy 44(1): 154-167.

Mellahi K, Wilkinson A. 2010. A Study of the Association between Level of Slack Reduction Following Downsizing and Innovation Output. Journal of Management Studies 47(3): 483-508.

Mowery DC. 2009. Plus Ca Change: Industrial R\&D in the “Third Industrial Revolution”. Industrial and Corporate Change 18(1): 1-50.

Mowery DC, Oxley JE, Silverman BS. 1996. Strategic Alliances and Interfirm Knowledge Transfer. Strategic Management Journal 17(Winter Special Issue): 77-91.

Nerkar A, Paruchuri S. 2005. Evolution of R\&D Capabilities: The Role of Knowledge Networks within a Firm. Management Science 51(5): 771-785.

Nerkar A, Shane S. 2007. Determinants of Invention Commercialization: An Empirical Examination of Academically Sourced Inventions. Strategic Management Journal 28(11): 1155-1166.

Obstfeld D. 2005. Social Networks, the Tertius Lungens Orientation, and Involvement in Innovation. Administrative Science Quarterly 50(1): 100-130.

Oxley J, Wada T. 2009. Alliance Structure and the Scope of Knowledge Transfer: Evidence from U.S.-Japan Agreements. Management Science 55(4): 635-649.

Pacheco-de-Almeida G, Zemsky P. 2007. The Timing of Resource Development and Sustainable Competitive Advantage. Management Science 53(4): 651-666.

Page SE. 2007. The Difference: How the Power of Diversity Creates Better Groups, Firms, Schools, and Societies. Princeton University Press: Princeton, NJ.

Paruchuri S. 2010. Intraorganizational Networks, Interorganizational Networks, and the Impact of Central Inventors: A Longitudinal Study of Pharmaceutical Firms. Organization Science 21(1): 63-80.

Paruchuri S, Awate S. 2017. Organizational Knowledge Networks and Local Search: The Role of Intra-Organizational Inventor Networks. Strategic Management Journal 38(3): 657-675.

Paruchuri S, Nerkar A, Hambrick DC. 2006. Acquisition Integration and Productivity Losses in the Technical Core: Disruption of Inventors in Acquired Companies. Organization Science 17(5): 545-562.

Pavitt KLR. 1998. Technologies, Products and Organization in the Innovating Firm: What Adam Smith Tells Us and Joseph Schumpeter Doesn't. Industrial and Corporate Change 7: 433-452.

Reagans R, McEvily B. 2003. Network Structure and Knowledge Transfer: The Effects of Cohesion and Range. Administrative Science Quarterly 48(2): 240-267.

Roberts EB, Hauftman O. 1987. The Financing Threshold Effect on Succes and Failure of Biomedical and Pharmaceutical Start-Ups. Management Science 33: 3-5.

Roberts EB, Hauptman O. 1987. The Financing Threshold Effect on Success and Failure of Biomedical and Pharmaceutical Start-Ups. Management Science 33(3): 381-394. 
Roberts PW. 1999. Product Innovation, Product-Market Competition and Persistent Profitability in the U.S. Pharmaceutical Industry. Strategic Management Journal 20: 655-670.

Rodan S, Galunic C. 2004. More Than Network Structure: How Knowledge Heterogeneity Influences Managerial Performance and Innovativeness. Strategic Management Journal 25(6): 541-562.

Rosenkopf L, Almeida P. 2003. Overcoming Local Search through Alliances and Mobility. Management Science 49(6): 751-766.

Scherer FM. 1967. Research and Development Resource Allocation under Rivalry. The Quarterly Journal of Economics 81(3): 359-394.

Schilling MA. 2009. Understanding the Alliance Data. Strategic Management Journal 30(3): 233-260.

Schoonhoven CB, Eisenhardt KM, Lyman K. 1990. Speeding Products to Market : Waiting Time to First Product Introduction in New Firms Claudia Bird Schoonhoven. Administrative Science Quarterly 35: 177-207.

Singh J. 2005. Collaborative Networks as Determinants of Knowledge Diffusion Patterns. Management Science 51(5): 756-770.

Singh J, Hansen MT, Podolny JM. 2010. The World Is Not Small for Everyone: Inequity in Searching for Knowledge in Organizations. Management Science 56(9): 1415-1438.

Sorenson O, Rivkin JW, Fleming L. 2006. Complexity, Networks and Knowledge Flow. Research Policy 35(7): 994-1017.

Srikanth K, Puranam P. 2011. Integrating Distributed Work: Comparing Task Design, Communication, and Tacit Coordination Mechanisms. Strategic Management Journal 32(8): 849-875.

Todorova G, Durisin B. 2007. Absorptive Capacity: Valuing a Reconceptualization. Academy of Management Review 32(3): 774-786.

Tortoriello M. 2015. The Social Underpinnings of Absorptive Capacity: The Moderating Effects of Structural Holes on Innovation Generation Based on External Knowledge. Strategic Management Journal 36(4): 586-597.

Tortoriello M, Krackhardt D. 2010. Activating Cross-Boundary Knowledge: The Role of Simmelian Ties in the Generation of Innovations. Academy of Management Journal 53(1): 167-181.

Tsai W. 2001. Knowledge Transfer in Intraorganizational Networks: Effects of Network Position and Absorptive Capacity on Business Unit Innovation and Performance. The Academy of Management Journal 44(5): 996-1004.

Tushman ML, Scanlan TJ. 1981. Boundary Spanning Individuals: Their Role in Information Transfer and Their Antecedents. The Academy of Management Journal 24(2): 289-305.

Tzabbar D, Aharonson BS, Amburgey TL. 2013. When Does Tapping External Sources of Knowledge Result in Knowledge Integration? Research Policy 42(2): 481-494.

Tzabbar D, Kehoe RR. 2014. Can Opportunity Emerge from Disarray? An Examination of Exploration and Exploitation Following Star Scientist Turnover. Journal of Management 40(2): 449-482.

Tzabbar D, Silverman BS, Aharonson BS. 2015. Learning by Hiring or Hiring to Avoid Learning? Journal of Managerial Psychology 30(5): 550-564.

Volberda HW, Foss NJ, Lyles MA. 2010. Absorbing the Concept of Absorptive Capacity: How to Realize Its Potential in the Organization Field. Organization Science 21(4): 931-951.

Zaheer A, Bell GG. 2005. Benefiting from Network Position: Firm Capabilities, Structural Holes, and Performance. Strategic Management Journal 26(9): 809-825.

Zahra SA, George G. 2002. Absorptive Capacity: A Review, Reconceptualization, and Extension. The Academy of Management Review 27(2): 185-203.

Ziedonis AA. 2007. Real Options in Technology Licensing. Management Science 53(10): 1618-1633. 


\section{Knowledge Diversity and Coordination}

Table 1. Descriptive Statistics and Correlation Coefficients ( $N=708)$

\begin{tabular}{|c|c|c|c|c|c|c|c|c|c|c|c|c|c|c|c|c|}
\hline & Variables & Mean & S.D. & (1) & $(2)$ & (3) & (4) & (5) & (6) & (7) & (8) & (9) & $(10)$ & $(11)$ & $(12)$ & $(13)$ \\
\hline (1) & "Technological Distance & 0.862 & 0.286 & 1.00 & & & & & & & & & & & & \\
\hline (2) & Intrafirm Inventor Task Network Diversity & 0.637 & 0.219 & -0.02 & 1.00 & & & & & & & & & & & \\
\hline (3) & Intrafirm Inventor Task Network Density & 0.155 & 0.189 & 0.06 & -0.52 & 1.00 & & & & & & & & & & \\
\hline (4) & Average Tie Strength & 1.723 & 1.116 & -0.07 & 0.12 & -0.17 & 1.00 & & & & & & & & & \\
\hline (5) & Clustering & 2.347 & 0.873 & -0.12 & 0.09 & 0.02 & 0.79 & 1.00 & & & & & & & & \\
\hline (6) & Average Path Length & 3.028 & 1.634 & 0.08 & 0.41 & -0.66 & 0.17 & 0.01 & 1.00 & & & & & & & \\
\hline (7) & R\&D Intensity & 119.466 & 113.908 & -0.10 & -0.19 & 0.40 & -0.02 & 0.05 & -0.38 & 1.00 & & & & & & \\
\hline (8) & Previous Year Patent & 0.962 & 0.192 & 0.09 & 0.40 & -0.29 & 0.06 & 0.05 & 0.17 & -0.02 & 1.00 & & & & & \\
\hline (9) & Prior Citations & 0.667 & 3.296 & -0.03 & -0.01 & 0.16 & -0.04 & 0.03 & -0.12 & -0.03 & 0.04 & 1.00 & & & & \\
\hline (10) & Co-Patent & 0.989 & 0.106 & 0.15 & 0.05 & -0.00 & 0.05 & 0.07 & 0.02 & 0.10 & 0.54 & 0.02 & 1.00 & & & \\
\hline (11) & Geographical Dispersion of Inventors & 0.183 & 0.177 & -0.08 & 0.10 & -0.13 & -0.02 & -0.06 & 0.21 & -0.05 & -0.22 & -0.09 & -0.42 & 1.00 & & \\
\hline (12) & Number of Star Scientists & 8.468 & 14.497 & 0.01 & 0.27 & -0.37 & 0.30 & 0.21 & 0.59 & -0.27 & 0.11 & -0.04 & 0.06 & 0.05 & 1.00 & \\
\hline (13) & Log (Number Employees) & 7.460 & 2.716 & 0.09 & 0.28 & -0.62 & 0.13 & -0.00 & 0.68 & -0.67 & 0.10 & -0.15 & -0.05 & 0.26 & 0.48 & 1.00 \\
\hline (14) & Slack & 188.629 & 132.908 & -0.02 & 0.22 & -0.47 & 0.36 & 0.21 & 0.44 & -0.28 & 0.12 & -0.15 & -0.02 & 0.14 & 0.38 & 0.60 \\
\hline (15) & US Firm & 0.871 & 0.335 & 0.00 & -0.09 & 0.19 & -0.00 & -0.05 & -0.14 & 0.08 & -0.03 & 0.08 & 0.04 & -0.31 & -0.03 & -0.21 \\
\hline (16) & Technological Furnishing & 0.627 & 0.484 & -0.00 & 0.14 & -0.22 & -0.07 & -0.08 & 0.26 & -0.04 & 0.11 & -0.07 & -0.08 & 0.05 & 0.10 & 0.09 \\
\hline (17) & Grant-back Clause & 0.253 & 0.435 & -0.02 & 0.03 & -0.13 & -0.07 & -0.19 & 0.12 & -0.20 & -0.00 & -0.04 & -0.15 & 0.02 & 0.03 & 0.15 \\
\hline (18) & Milestone & 0.629 & 0.484 & -0.09 & -0.21 & -0.03 & 0.12 & 0.15 & 0.08 & 0.11 & -0.06 & -0.04 & -0.05 & -0.02 & 0.10 & 0.10 \\
\hline (19) & Technology Value & 54.767 & 135.985 & 0.03 & 0.09 & 0.05 & 0.02 & 0.07 & -0.03 & -0.09 & 0.04 & 0.03 & 0.03 & -0.04 & 0.00 & 0.03 \\
\hline (20) & Early Stage Technology & 0.278 & 0.448 & 0.00 & -0.12 & -0.03 & -0.12 & -0.20 & 0.04 & 0.14 & -0.11 & 0.08 & 0.07 & -0.00 & -0.03 & -0.06 \\
\hline (21) & Licensor University & 0.105 & 0.306 & 0.05 & -0.32 & 0.34 & -0.07 & -0.01 & -0.28 & 0.16 & -0.32 & 0.13 & 0.04 & -0.05 & -0.16 & -0.29 \\
\hline$(22)$ & Licensor Number of Patents & 197.154 & 540.838 & -0.13 & -0.18 & 0.34 & -0.05 & -0.00 & -0.27 & 0.03 & -0.14 & 0.05 & 0.03 & -0.19 & -0.15 & -0.18 \\
\hline (23) & Industry Competition & 0.003 & 0.020 & -0.00 & 0.16 & 0.09 & 0.00 & 0.07 & -0.01 & -0.09 & 0.03 & -0.02 & 0.02 & -0.06 & -0.06 & 0.02 \\
\hline \multirow[t]{2}{*}{ (24) } & Market Growth & 0.106 & 0.124 & 0.01 & -0.14 & 0.08 & -0.06 & -0.22 & -0.07 & 0.05 & -0.07 & 0.03 & -0.09 & -0.11 & -0.01 & -0.19 \\
\hline & Variables & Mean & S.D. & $(14)$ & (15) & $(16)$ & $(17)$ & $(18)$ & $(19)$ & $(20)$ & $(21)$ & $(22)$ & $(23)$ & $(24)$ & & \\
\hline$(14)$ & Slack & 188.629 & 132.908 & 1.00 & & & & & & & & & & & & \\
\hline (15) & US Firm & 0.871 & 0.335 & -0.20 & 1.00 & & & & & & & & & & & \\
\hline (16) & Technological Furnishing & 0.627 & 0.484 & 0.13 & -0.14 & 1.00 & & & & & & & & & & \\
\hline (17) & Grant-back Clause & 0.253 & 0.435 & 0.11 & -0.05 & 0.13 & 1.00 & & & & & & & & & \\
\hline (18) & Milestone & 0.629 & 0.484 & 0.18 & -0.07 & -0.01 & 0.02 & 1.00 & & & & & & & & \\
\hline (19) & Technology Value & 54.767 & 135.985 & -0.02 & 0.00 & -0.13 & -0.07 & -0.01 & 1.00 & & & & & & & \\
\hline (20) & Early Stage Technology & 0.278 & 0.448 & -0.06 & 0.01 & -0.11 & 0.03 & 0.20 & -0.02 & 1.00 & & & & & & \\
\hline$(21)$ & Licensor University & 0.105 & 0.306 & -0.31 & 0.03 & -0.31 & -0.17 & 0.04 & -0.04 & 0.26 & 1.00 & & & & & \\
\hline (22) & Licensor Number of Patents & 197.154 & 540.838 & -0.19 & 0.12 & -0.06 & 0.21 & 0.13 & -0.08 & 0.00 & 0.07 & 1.00 & & & & \\
\hline (23) & Industry Competition & 0.003 & 0.020 & -0.06 & 0.06 & 0.01 & -0.10 & -0.18 & 0.37 & -0.09 & -0.06 & -0.05 & 1.00 & & & \\
\hline (24) & Market Growth & 0.106 & 0.124 & -0.08 & 0.06 & 0.05 & 0.31 & -0.02 & -0.03 & 0.02 & -0.03 & -0.01 & -0.30 & 1.00 & & \\
\hline
\end{tabular}




\section{Knowledge Diversity and Coordination}

Table2. Results of Log-Logistic Hazard Models Predicting the Speed of Knowledge Absorption

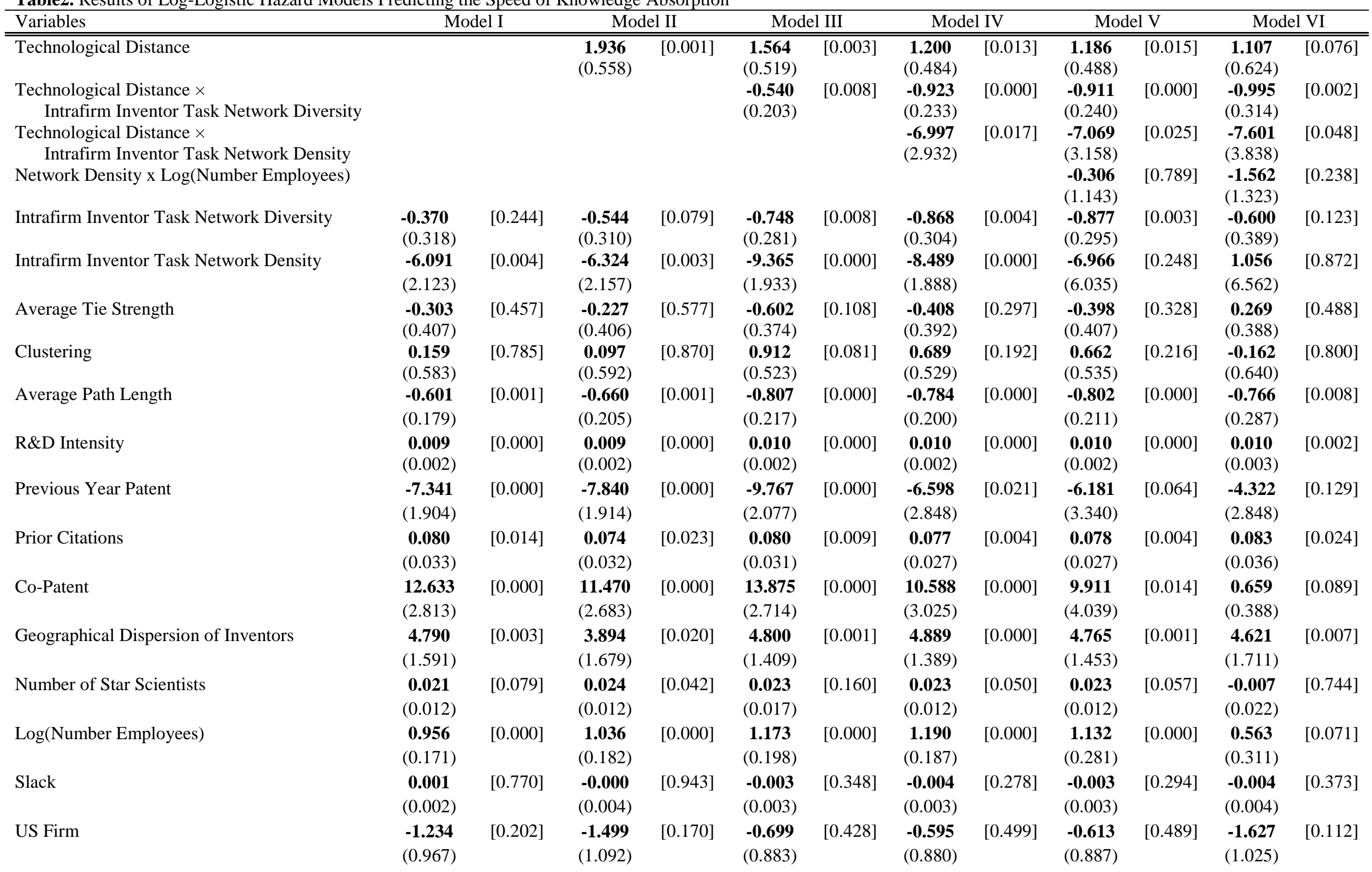


Knowledge Diversity and Coordination

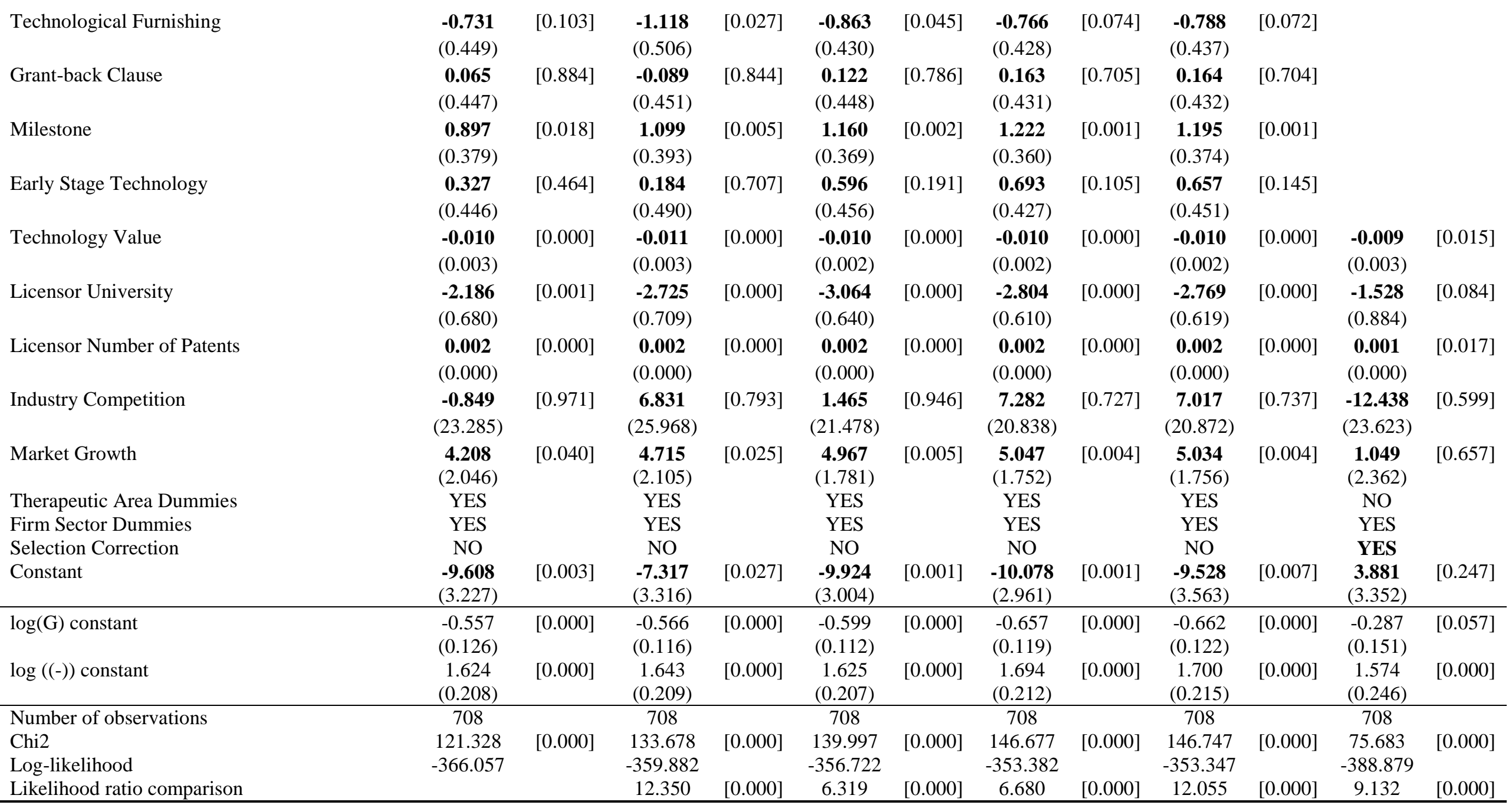

Estimated coefficients are in bold. Standard errors are in parentheses. P-values are between square brackets. All tests are two tailed. 


\section{Knowledge Diversity and Coordination}

Table 3. Log-logistic Hazard Models Predicting the Speed of Knowledge Absorption

\begin{tabular}{|c|c|c|c|c|c|c|c|c|c|c|c|c|}
\hline \multirow{3}{*}{$\begin{array}{r}\text { Variables } \\
\text { Technological Distance }\end{array}$} & \multicolumn{6}{|c|}{ Time Varying Explanatory Variables } & \multicolumn{6}{|c|}{ With Firm Dummies } \\
\hline & \multicolumn{2}{|c|}{ Model I } & \multicolumn{2}{|c|}{ Model II } & \multicolumn{2}{|c|}{ Model III } & \multicolumn{2}{|c|}{ Model IV } & \multicolumn{2}{|c|}{ Model V } & \multicolumn{2}{|c|}{ Model VI } \\
\hline & & & $\begin{array}{c}1.344 \\
(0.639)\end{array}$ & {$[0.035]$} & $\begin{array}{c}\mathbf{6 . 8 1 0} \\
(2.431)\end{array}$ & {$[0.005]$} & & & $\begin{array}{c}1.307 \\
(0.689)\end{array}$ & $\begin{array}{l}{[0.058]} \\
(0.610)\end{array}$ & 1.238 & {$[0.042]$} \\
\hline $\begin{array}{l}\text { Technological Distance } \times \\
\text { Intrafirm Inventor Task Network Diversity }\end{array}$ & & & & & $\begin{array}{l}-8.205 \\
(4.290)\end{array}$ & {$[0.056]$} & & & & & $\begin{array}{l}-\mathbf{6 . 4 1 0} \\
(2.586)\end{array}$ & [0.013] \\
\hline $\begin{array}{l}\text { Technological Distance } \times \\
\text { Intrafirm Inventor Task Network Density }\end{array}$ & & & & & $\begin{array}{r}-\mathbf{- 1 0 . 2 7 3} \\
(3.561)\end{array}$ & {$[0.004]$} & & & & & $\begin{array}{l}\mathbf{- 1 1 . 8 9 7} \\
(3.681)\end{array}$ & [0.001] \\
\hline Intrafirm Inventor Task Network Diversity & $\begin{array}{c}1.998 \\
(1.926)\end{array}$ & {$[0.300]$} & $\begin{array}{c}1.446 \\
(1.507)\end{array}$ & [0.337] & $\begin{array}{c}8.333 \\
(4.311)\end{array}$ & {$[0.053]$} & $\begin{array}{l}\mathbf{- 1 7 . 5 3 2} \\
(6.664)\end{array}$ & {$[0.009]$} & $\begin{array}{l}\mathbf{- 1 6 . 9 9 3} \\
(6.507)\end{array}$ & $\begin{array}{l}{[0.009]} \\
(5.711)\end{array}$ & -16.806 & {$[0.003]$} \\
\hline Intrafirm Inventor Task Network Density & $\begin{array}{l}\mathbf{- 1 . 9 7 5} \\
(1.583)\end{array}$ & {$[0.212]$} & $\begin{array}{c}-2.169 \\
(1.501)\end{array}$ & [0.149] & $\begin{array}{l}\mathbf{- 1 . 6 2 0} \\
(1.465)\end{array}$ & {$[0.269]$} & $\begin{array}{l}-30.212 \\
(11.541)\end{array}$ & {$[0.009]$} & $\begin{array}{l}-24.580 \\
(11.176)\end{array}$ & $\begin{array}{l}{[0.028]} \\
(9.350)\end{array}$ & -21.439 & {$[0.022]$} \\
\hline Average Tie Strength & $\begin{array}{c}\mathbf{0 . 2 2 2} \\
(0.309)\end{array}$ & {$[0.471]$} & $\begin{array}{c}\mathbf{0 . 2 2 6} \\
(0.308)\end{array}$ & [0.463] & $\begin{array}{c}\mathbf{0 . 0 9 2} \\
(0.168)\end{array}$ & [0.582] & $\begin{array}{c}3.717 \\
(1.248)\end{array}$ & [0.003] & $\begin{array}{c}4.131 \\
(1.249)\end{array}$ & $\begin{array}{l}{[0.001]} \\
(1.146)\end{array}$ & 4.317 & {$[0.000]$} \\
\hline Clustering & $\begin{array}{c}\mathbf{2 . 0 8 9} \\
(1.682)\end{array}$ & {$[0.214]$} & $\begin{array}{c}1.518 \\
(1.696)\end{array}$ & {$[0.371]$} & $\begin{array}{c}1.302 \\
(1.554)\end{array}$ & {$[0.402]$} & $\begin{array}{c}-2.858 \\
(1.320)\end{array}$ & {$[0.030]$} & $\begin{array}{l}-3.154 \\
(1.307)\end{array}$ & $\begin{array}{l}{[0.016]} \\
(1.212)\end{array}$ & -3.152 & [0.009] \\
\hline Average Path Length & $\begin{array}{l}\mathbf{- 1 . 2 6 7} \\
(0.362)\end{array}$ & {$[0.000]$} & $\begin{array}{c}\mathbf{- 1 . 3 0 0} \\
(0.296)\end{array}$ & {$[0.000]$} & $\begin{array}{l}-\mathbf{- 1 . 1 4 7} \\
(0.308)\end{array}$ & {$[0.000]$} & $\begin{array}{l}\mathbf{- 0 . 0 4 7} \\
(0.195)\end{array}$ & [0.809] & $\begin{array}{c}-\mathbf{0 . 0 8 4} \\
(0.195)\end{array}$ & $\begin{array}{l}{[0.668]} \\
(0.196)\end{array}$ & -0.066 & [0.737] \\
\hline R\&D Intensity & $\begin{array}{c}\mathbf{0 . 0 0 2} \\
(0.014)\end{array}$ & {$[0.896]$} & $\begin{array}{c}\mathbf{- 0 . 0 0 1} \\
(0.012)\end{array}$ & [0.956] & $\begin{array}{c}\mathbf{0 . 0 0 6} \\
(0.025)\end{array}$ & {$[0.814]$} & & & & & & \\
\hline Previous Year Patent & $\begin{array}{c}-4.270 \\
(1.971)\end{array}$ & {$[0.030]$} & $\begin{array}{c}-5.153 \\
(2.002)\end{array}$ & {$[0.010]$} & $\begin{array}{c}-\mathbf{6 . 5 1 3} \\
(2.080)\end{array}$ & {$[0.002]$} & & & & & & \\
\hline Prior Citations & $\begin{array}{c}\mathbf{- 0 . 1 0 0} \\
(0.052)\end{array}$ & {$[0.057]$} & $\begin{array}{c}\mathbf{- 0 . 0 9 8} \\
(0.040)\end{array}$ & [0.015] & $\begin{array}{c}\mathbf{- 0 . 1 0 8} \\
(0.030)\end{array}$ & {$[0.000]$} & & & & & & \\
\hline Co-Patent & $\begin{array}{c}\mathbf{0 . 0 9 9} \\
(0.557)\end{array}$ & {$[0.860]$} & $\begin{array}{c}\mathbf{0 . 3 3 9} \\
(0.547)\end{array}$ & [0.535] & $\begin{array}{c}\mathbf{0 . 2 3 1} \\
(0.551)\end{array}$ & {$[0.674]$} & & & & & & \\
\hline Geographical Dispersion of Inventors & $\begin{array}{c}\mathbf{0 . 6 7 5} \\
(1.739)\end{array}$ & {$[0.698]$} & $\begin{array}{c}\mathbf{0 . 5 8 9} \\
(1.789)\end{array}$ & {$[0.742]$} & $\begin{array}{c}-\mathbf{0 . 7 3 2} \\
(1.749)\end{array}$ & {$[0.675]$} & & & & & & \\
\hline Number of Star Scientists & $\begin{array}{c}\mathbf{- 0 . 0 1 9} \\
(0.019)\end{array}$ & [0.328] & $\begin{array}{c}\mathbf{- 0 . 0 1 8} \\
(0.018)\end{array}$ & [0.333] & $\begin{array}{c}\mathbf{- 0 . 0 1 7} \\
(0.020)\end{array}$ & [0.399] & & & & & & \\
\hline Log (Number Employees) & $\begin{array}{c}\mathbf{0 . 5 0 5} \\
(0.140)\end{array}$ & {$[0.000]$} & $\begin{array}{c}\mathbf{0 . 5 3 0} \\
(0.135)\end{array}$ & {$[0.000]$} & $\begin{array}{c}\mathbf{0 . 3 6 3} \\
(0.162)\end{array}$ & {$[0.024]$} & & & & & & \\
\hline Slack & $\begin{array}{c}\mathbf{1 . 1 0 8} \\
(1.905)\end{array}$ & {$[0.561]$} & $\begin{array}{c}\mathbf{1 . 4 7 9} \\
(1.761)\end{array}$ & [0.401] & $\begin{array}{c}-\mathbf{0 . 0 0 0} \\
(4.152)\end{array}$ & {$[1.000]$} & & & & & & \\
\hline US Firm & $\begin{array}{c}\mathbf{4 . 3 5 2} \\
(1.689)\end{array}$ & {$[0.010]$} & $\begin{array}{c}\mathbf{4 . 3 9 4} \\
(1.397)\end{array}$ & [0.002] & $\begin{array}{c}\mathbf{5 . 5 2 0} \\
(1.229)\end{array}$ & {$[0.000]$} & & & & & & \\
\hline Technological Furnishing & $\begin{array}{c}\mathbf{- 0 . 6 0 2} \\
(0.513)\end{array}$ & {$[0.241]$} & $\begin{array}{c}\mathbf{- 0 . 8 0 4} \\
(0.522)\end{array}$ & [0.124] & $\begin{array}{c}\mathbf{- 0 . 6 4 7} \\
(0.484)\end{array}$ & {$[0.181]$} & & & & & & \\
\hline Grant-back Clause & $\begin{array}{c}\mathbf{0 . 9 1 6} \\
(0.629)\end{array}$ & {$[0.146]$} & $\begin{array}{c}\mathbf{1 . 0 1 6} \\
(0.583)\end{array}$ & [0.081] & $\begin{array}{c}1.295 \\
(0.565)\end{array}$ & [0.022] & & & & & & \\
\hline
\end{tabular}


Knowledge Diversity and Coordination

\begin{tabular}{|c|c|c|c|c|c|c|c|c|c|c|c|c|}
\hline Milestone & $\begin{array}{c}\mathbf{0 . 7 4 9} \\
(0.480)\end{array}$ & [0.119] & $\begin{array}{c}\mathbf{0 . 9 1 6} \\
(0.469)\end{array}$ & {$[0.051]$} & $\begin{array}{c}\mathbf{0 . 5 9 1} \\
(0.521)\end{array}$ & {$[0.257]$} & & & & & & \\
\hline Technology Value & $\begin{array}{l}-\mathbf{0 . 0 1 5} \\
(0.003)\end{array}$ & [0.000] & $\begin{array}{l}-\mathbf{0 . 0 1 5} \\
(0.003)\end{array}$ & {$[0.000]$} & $\begin{array}{l}-\mathbf{0 . 0 1 3} \\
(0.003)\end{array}$ & {$[0.000]$} & & & & & & \\
\hline \multirow[t]{2}{*}{ Early Stage Technology } & 0.458 & [0.449] & 0.456 & {$[0.436]$} & 0.701 & {$[0.208]$} & & & & & & \\
\hline & -0.605 & & -0.586 & & -0.557 & & & & & & & \\
\hline Licensor University & $\begin{array}{l}\mathbf{- 0 . 9 9 7} \\
(0.659)\end{array}$ & [0.130] & $\begin{array}{c}\mathbf{- 1 . 1 3 6} \\
(0.635)\end{array}$ & {$[0.074]$} & $\begin{array}{l}\mathbf{- 1 . 0 9 9} \\
(0.632)\end{array}$ & {$[0.082]$} & & & & & & \\
\hline Licensor Number of Patents & $\begin{array}{c}-\mathbf{0 . 0 0 0} \\
(0.000)\end{array}$ & [0.238] & $\begin{array}{c}-\mathbf{0 . 0 0 0} \\
(0.000)\end{array}$ & {$[0.414]$} & $\begin{array}{l}-\mathbf{0 . 0 0 0} \\
(0.000)\end{array}$ & {$[0.428]$} & & & & & & \\
\hline Industry Competition & $\begin{array}{c}\mathbf{- 1 3 . 2 4 7} \\
(9.579)\end{array}$ & [0.167] & $\begin{array}{c}\mathbf{- 1 0 . 8 5 0} \\
(8.870)\end{array}$ & {$[0.221]$} & $\begin{array}{c}\mathbf{- 1 1 . 9 7 7} \\
(8.900)\end{array}$ & {$[0.178]$} & & & & & & \\
\hline Market Growth & $\begin{array}{l}-2.379 \\
(1.014)\end{array}$ & {$[0.019]$} & $\begin{array}{c}-2.397 \\
(0.978)\end{array}$ & {$[0.014]$} & $\begin{array}{c}-2.563 \\
(1.130)\end{array}$ & {$[0.023]$} & & & & & & \\
\hline Therapeutic Area Dummies & YES & & YES & & YES & & NO & & $\mathrm{NO}$ & & NO & \\
\hline Firm Sector Dummies & YES & & YES & & YES & & NO & & NO & & NO & \\
\hline Firm Dummies & NO & & NO & & NO & & YES & & YES & & YES & \\
\hline Constant & $\begin{array}{l}\mathbf{1 0 . 5 3 1} \\
(2.764)\end{array}$ & {$[0.000]$} & $\begin{array}{l}\mathbf{1 2 . 7 9 2} \\
(2.915)\end{array}$ & {$[0.000]$} & $\begin{array}{l}\mathbf{1 3 . 2 8 8} \\
(2.718)\end{array}$ & {$[0.000]$} & $\begin{array}{c}\mathbf{1 . 5 8 6} \\
(2.026)\end{array}$ & {$[0.434]$} & $\begin{array}{c}1.752 \\
(1.867)\end{array}$ & $\begin{array}{l}{[0.348]} \\
(1.690)\end{array}$ & 2.209 & [0.191] \\
\hline $\log (\mathrm{G})$ constant & $\begin{array}{l}-0.377 \\
(0.162)\end{array}$ & {$[0.020]$} & $\begin{array}{c}-0.378 \\
(0.155)\end{array}$ & {$[0.015]$} & $\begin{array}{c}-0.611 \\
(0.201)\end{array}$ & {$[0.002]$} & $\begin{array}{c}-0.521 \\
(0.128)\end{array}$ & {$[0.000]$} & $\begin{array}{l}-0.505 \\
(0.121)\end{array}$ & $\begin{array}{l}{[0.000]} \\
(0.122)\end{array}$ & -0.560 & {$[0.000]$} \\
\hline $\log ((-))$ constant & $\begin{array}{c}2.064 \\
(0.209)\end{array}$ & {$[0.000]$} & $\begin{array}{c}2.067 \\
(0.211)\end{array}$ & {$[0.000]$} & $\begin{array}{c}2.252 \\
(0.198)\end{array}$ & {$[0.000]$} & $\begin{array}{c}-0.578 \\
(0.322)\end{array}$ & {$[0.073]$} & $\begin{array}{c}-0.641 \\
(0.313)\end{array}$ & $\begin{array}{l}{[0.040]} \\
(0.309)\end{array}$ & -0.610 & [0.048] \\
\hline Number of observations & 4.802 & & 4.802 & & 4.802 & & 708 & & 708 & & 708 & \\
\hline Chi2 & 165.100 & {$[0.000]$} & 169.665 & {$[0.000]$} & 181.681 & {$[0.000]$} & 226.745 & {$[0.000]$} & 230.565 & {$[0.000]$} & 242.374 & {$[0.000]$} \\
\hline Log-likelihood & -534.850 & & -532.567 & & -526.559 & & -313.348 & & -311.438 & & -305.534 & \\
\hline Likelihood ratio comparison & & & 4.565 & {$[0.000]$} & 12.016 & {$[0.000]$} & & & 3.820 & {$[0.000]$} & 11.808 & {$[0.000]$} \\
\hline
\end{tabular}

Estimated coefficients are in bold. Standard errors are in parentheses. P-values are between square brackets. All tests are two tailed. 


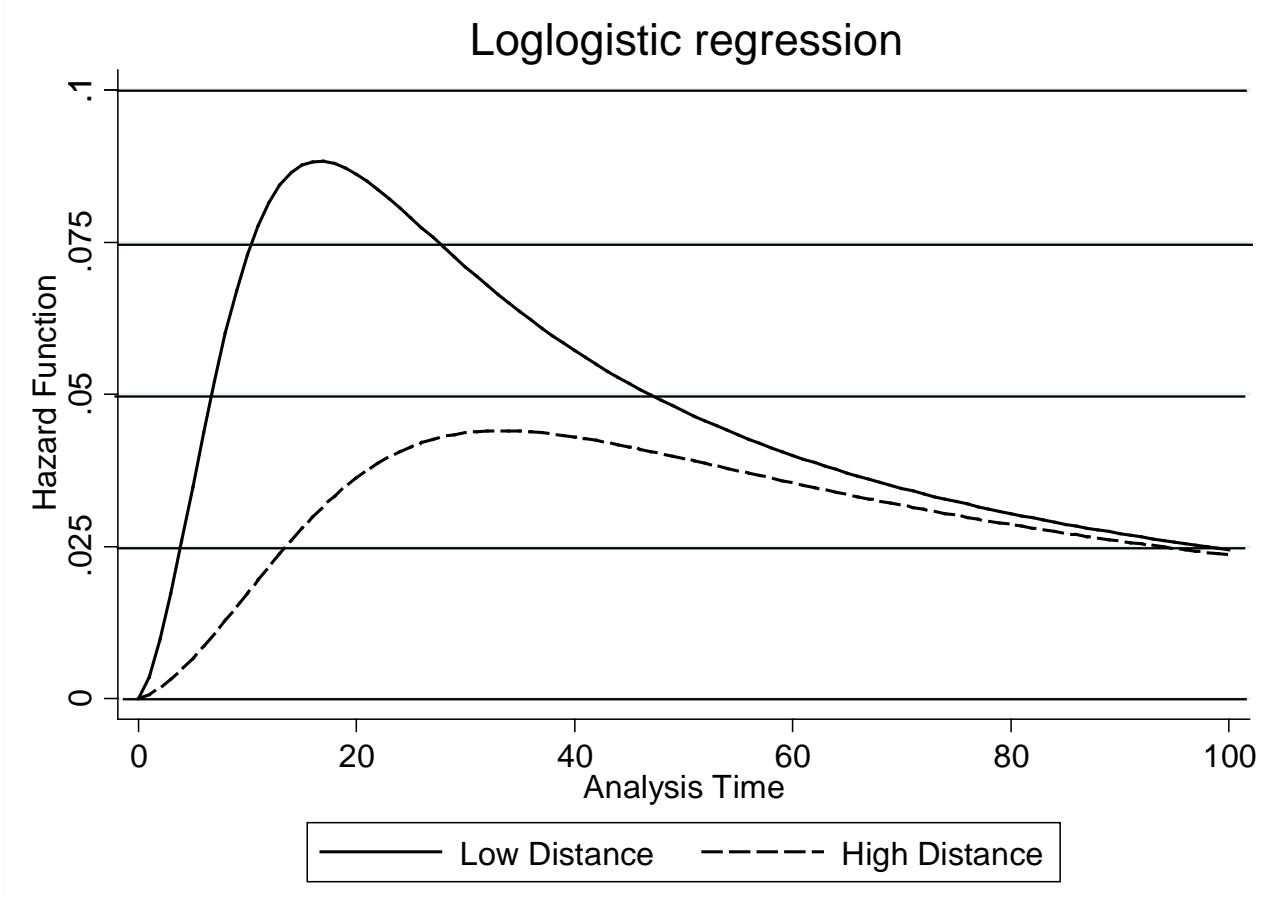

Figure 1. Estimated Hazard Functions of Small versus Large Distance Licensed Technologies 